\title{
BIONANOCOMPÓSITOS POLIMÉRICOS À BASE DE MONTMORILLONITA - MATERIAIS DE INTERESSE CONTÍNUO
}

\author{
Denise B. França a , Ana C. S. Alcântara ${ }^{\mathrm{b}}$, Edson C. Silva-Filhoc e Maria G. Fonseca,*,(i)

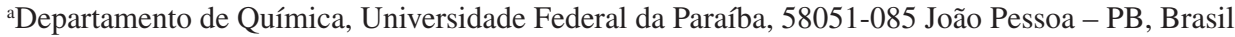 \\ bDepartamento de Química, Universidade Federal do Maranhão, 65080-805 São Luiz - MA, Brasil \\ 'Departamento de Química, Universidade Federal do Piauí, 64049-550 Teresina - PI, Brasil
}

Recebido em 06/03/2020; aceito em 15/06/2020; publicado na web em 03/08/2020

\begin{abstract}
POLYMERIC BIONANOCOMPOSITES BASED ON MONTMORILLONITE - MATERIALS IN CONTINUOUS INTEREST. Polymeric bionanocomposites are versatile materials that have many practical applications. The wide use of these materials is mainly due to their structure and properties, which combine at nanometric scale, the functionality of biopolymers with the excellent stability of inorganic solids, such as the clay minerals family. Montmorillonite is the most widely employed clay mineral in the development of polymeric bionanocomposites. The resulting materials from the combination of biopolymers and montmorillonite clay can form different structures (layered, delaminated, and exfoliated phases) and morphologies (powder, films or beads), exhibiting new features and better chemical, mechanical, thermal, and gas barrier properties compared to the pristine matrices, owing to the synergistic effect between both organic and inorganic moieties. In this sense, this review addresses polymeric bionanocomposites originating from the interaction between montmorillonite and chitosan and cellulose biopolymers. The synthesis, characteristics, and main applications of polymeric bionanocomposites have been reported, and in some cases, the relationship between the formed structures and final properties of bionanocomposites is also highlighted.
\end{abstract}

Keywords: bionanocomposite; clay minerals; montmorillonite; chitosan; cellulose.

\section{INTRODUÇÃO}

A incorporação de filossilicatos em polímeros derivados do petróleo deu origem aos chamados nanocompósitos poliméricos, cujas propriedades obtidas não são observadas em materiais de partida. Segundo a IUPAC, ${ }^{1}$ diferentemente do que ocorre nos compósitos, a formação do nanocompósito argila/polímero dá-se pela dispersão da matriz inorgânica - nesse caso, o filossilicato - no polímero, a partir de uma elevada interação interfacial em escala manométrica.

A combinação em escala molecular leva à formação de um novo material, com propriedades melhoradas, incluindo as mecânicas, a exemplo de tração, módulo, resistência à fratura; as propriedades de barreira, como permeabilidade e resistência a solventes e gases; as propriedades ópticas e de condutividade iônica, estabilidade térmica e retardância à chama, quando comparados à matriz original e aos compósitos.

Os trabalhos pioneiros nesse campo ${ }^{2,3}$ tratavam da formação de nanocompósitos de argila com polímeros acrílicos a partir da polimerização dos monômeros de metacrilato ${ }^{2}$ e metacrilato de metila ${ }^{3}$ adsorvidos em montmorillonita. Nos anos 1990, a esfoliação da montmorillonita em nylon 6 (uma poliamida) pelos pesquisadores da Toyota resultou em materiais melhorados com propriedades mecânicas e de barreira contra água e gases, os quais foram posteriormente aplicados na indústria automobilística. ${ }^{4-6}$

Na sequência, nanocompósitos de montmorillonita/epóxi foram obtidos ${ }^{7,8}$ e ampliados para outros tipos de polímeros, como poliestireno, polietileno, poli(cloreto de vinila) (PVC), poli[(etileno)-co-(acetato de vinila)] (EVA), entre outros. ${ }^{9,10}$

Diversas revisões e capítulos de livro na literatura especializada dão conta da formação de nanocompósitos poliméricos com diferentes argilominerais, incluindo a montimorillonita,,${ }^{9,11,12}$ a caulinita, ${ }^{13}$ a paligorsquita e sepiolita, ${ }^{14,15}$ entre outros. No que se refere

*e-mail: mgardennia@quimica.ufpb.br aos nanocompósitos poliméricos com argilominerais para uso em embalagens na área de alimentos, as propriedades de barreira são importantes, mas o polímero a ser utilizado deve ser biodegradável. ${ }^{9}$

Nesse sentido, o uso de biopolímeros aparece como alternativa aos polímeros derivados de petróleo em nanocompósitos poliméricos convencionais, dando origem aos bionanocompósitos poliméricos. A biodegradabilidade dos materiais obtidos, resultantes da incorporação de argilominerais nos biopolímeros, é uma propriedade essencial para o desenvolvimento de bioplásticos que ajudam a reduzir a poluição causada por resíduos plásticos. ${ }^{16,17}$ Esses novos materiais são, portanto, constituídos por componentes não tóxicos e facilmente degradados por microrganismos. Outro motivo para a produção desses bionanocompósitos é a grande disponibilidade de biopolímeros na natureza, como amido, celulose e quitina, além de as fontes serem renováveis. ${ }^{16}$

Os materiais compósitos ou nanocompósitos poliméricos são, também, materiais híbridos inorgânicos-orgânicos, ${ }^{18}$ cujas definições serão apresentadas adiante. Os bionanocompósitos à base de biopolímeros e argilominerais constituem, portanto, uma classe de materiais que se tornam cada vez mais relevantes na sociedade, e suas aplicações têm transitado por diversas áreas, além do uso para embalagens na indústria alimentícia. O crescente interesse por esses sistemas surge como consequência de suas características variadas, resultantes da união da funcionalidade dos biopolímeros à estabilidade do sólido inorgânico em uma escala nanométrica, proporcionando um sinergismo de suas propriedades iniciais. ${ }^{19-21}$

Os argilominerais são filossilicatos que contam com uma rica variedade estrutural, podendo ser de origem natural ou sintética. ${ }^{22-28}$ Uma de suas principais características, que possibilita a obtenção de bionanocompósitos poliméricos, é a fraca interação ao longo da direção de empilhamento das lamelas, que redundam em uma reatividade especial na região interlamelar. ${ }^{29,30}$

Entre os argilominerais, a montmorillonita (Mt) tem-se destacado no desenvolvimento desses sistemas, ${ }^{31-34}$ por pertencer a uma classe 
de filossilicatos expansíveis e apresentar notável capacidade de adsorção, ${ }^{35}$ intercalação ${ }^{25,36}$ e troca iônica, ${ }^{37,38}$ além de propriedades de intumescimento ${ }^{39,40}$ que facultam a sua interação com os biopolímeros.

Os biopolímeros são definidos pela IUPAC ${ }^{41}$ como macromoléculas (proteínas, ácidos nucleicos e polissacarídeos) formadas por organismos vivos. Entre os polissacarídeos, celulose, ${ }^{33,42,43}$ quitosana (CS), ${ }^{44-47}$ amido, ${ }^{48-51}$ pectina, ${ }^{52,53}$ alginato, ${ }^{32,54,55}$ goma xantana, ${ }^{32}$ entre outros, têm sido utilizados na preparação de bionanocompósitos poliméricos com a Mt. Todavia, os materiais nanocompósitos baseados em celulose e CS suscitam um interesse particular por serem biopolímeros abundantes na natureza ${ }^{56-60}$ e exibirem determinadas características estruturais e grupos funcionais que são responsáveis pela maioria de suas propriedades e interações com os argilominerais. ${ }^{20,40,61}$

No caso da Mt, a presença de carga negativa permanente em suas lamelas e cátions trocáveis na região interlamelar favorecem a sua interação com espécies polares neutras ou catiônicas, como a celulose e a CS, respectivamente ${ }^{39,40,62,63}$ - essas, aliadas à abundância e ao baixo custo do argilomineral, justificam a extensa pesquisa existente acerca desses bionanocompósitos.

A síntese desses sistemas é, muitas vezes, inspirada em bionanocompósitos formados por biopolímeros e sólidos inorgânicos encontrados na natureza, a exemplo do nacre (também conhecido como madrepérola ou nácar) em pérolas e conchas, assim como os ossos e dentes, os quais possuem uma estrutura altamente ordenada de seus componentes. ${ }^{19,20}$

No entanto, a interação entre a Mt e os biopolímeros pode levar à formação de diferentes formas físicas (filmes, esferas, pós, membranas, entre outras) e estruturas, dependendo da composição, das condições experimentais e dos métodos de síntese empregados, os quais apresentam estreita relação com as propriedades observadas. ${ }^{64-68}$

Diante do leque de possibilidades, os bionanocompósitos poliméricos aparecem como alternativa ecologicamente viável para a substituição de polímeros sintéticos não biodegradáveis derivados do petróleo. ${ }^{27,69,70}$ Ao contrário dos biopolímeros utilizados isoladamente, os bionanocompósitos poliméricos combinam biodegradabilidade e biocompatibilidade com propriedades mecânicas, térmicas e de barreira aprimoradas, que são geralmente obtidas pela incorporação de pequenas quantidades de Mt. Consequentemente, esses materiais, também denominados nanocompósitos verdes ou bioplásticos, ${ }^{71}$ apresentam elevado potencial para aplicação tanto em indústrias de alimentos quanto em áreas biomédicas, elétricas e óptico-eletrônicas, entre outras..$^{19,70,72}$

Nessa direção, diversos trabalhos avaliam o desempenho desses materiais frente às novas propriedades apresentadas, propondo novas metodologias de síntese com o escopo de obter uma composição ideal dos constituintes onde haja maximização do efeito sinérgico para determinada aplicação. ${ }^{43,70,72,73}$

Sob outro ponto de vista, à parte da definição da IUPAC, muitos estudos consideram como bionanocompósitos os materiais híbridos originados a partir da modificação orgânica da Mt com a CS, por meio de reações de intercalação, ${ }^{9,45,46,74-77}$ de modo que o argilomineral é o componente preponderante no material resultante. Nessa perspectiva, novos grupos funcionais são introduzidos ao longo da região interlamelar e superfície da Mt, e podem atuar como novos sítios de interação para determinadas espécies onde pouca ou nenhuma afinidade era observada. ${ }^{45,78-80}$ Em virtude disso, bionanocompósitos poliméricos baseados em Mt e CS exibem um campo vasto de aplicação, que transita por áreas ambientais, ${ }^{45,64,81-83}$ catalíticas ${ }^{84-88}$ e biológicas, ${ }^{89-92}$ além de campos como agricultura ${ }^{90,93}$ e farmácia, ${ }^{91,94,95}$ entre outros.

No âmbito da presente revisão, será dada ênfase aos processos de síntese baseados na interação de biopolímeros com argilominerais como a montmorillonita, em duas situações experimentais distintas. Na primeira, a matriz polimérica encontra-se em maior proporção e um segundo tipo de material em que a matriz inorgânica está em maior proporção. Em ambos os casos, materiais híbridos são obtidos, cujas aplicações estão associadas às propriedades finais do material obtido.

Dessa forma, é necessário esclarecer que esses materiais resultam do efeito sinérgico das propriedades de ambos os componentes (Mt e biopolímero), promovido pela interação em escala nanométrica, ${ }^{75}$ com um diferencial que reside na capacidade de adaptação e ajuste de suas propriedades, de acordo com a aplicação desejada, denotando uma classe de materiais de grande interesse e aplicabilidade.

\section{ARGILOMINERAIS}

Os argilominerais são filossilicatos constituídos basicamente de lamelas formadas por folhas de tetraedros $\left[\mathrm{TO}_{4}\right]\left(\mathrm{T}=\mathrm{Si}^{4+}, \mathrm{Al}^{3+}\right.$ ou $\left.\mathrm{Fe}^{3+}\right)$ e octaedros $\left[\mathrm{MX}_{6}\right],\left(\mathrm{M}=\mathrm{Al}^{3+}, \mathrm{Mg}^{2+}\right.$ ou Fe ${ }^{2+}$; e $\mathrm{X}=\mathrm{O}$ ou $\left.\mathrm{OH}\right)$, unidos entre si em um arranjo bidimensional contínuo. Quando os tetraedros $\left[\mathrm{TO}_{4}\right]$ ligam-se a três outros tetraedros vizinhos, mediante compartilhamento dos vértices, uma folha tetraédrica é formada; por sua vez, a união entre os octaedros adjacentes, a partir do compartilhamento das arestas, dá origem à folha octaédrica, ambas com simetria hexagonal ou pseudo-hexagonal (Figura 1a e 1b)..$^{30,62,96}$

A união entre as folhas origina lamelas com dimensão nanométrica que podem exibir estruturas do tipo 1:1, quando uma folha tetraédrica está unida a uma octaédrica (Figura 1c); e do tipo 2:1, quando duas folhas tetraédricas estão ligadas a uma folha octaédrica central (Figura 1d). Nas lamelas 2:1, os octaedros mostram, ainda, duas topologias distintas que dependem das posições das hidroxilas, podendo ser: cis-orientada, se dispostas ao longo de uma aresta; ou trans-orientada, para uma disposição em lados opostos do octaedro. De acordo com a ocupação dos sítios na folha octaédrica, os argilominerais também podem ser classificados com trioctédricos, se todos os sítios octaédricos são ocupados com cátions divalentes $\left(\mathrm{M}^{2+}=\mathrm{Mg}^{2+}\right.$, $\mathrm{Fe}^{2+}$ ); ou dioctaédricos, se apenas $2 / 3$ desses sítios estão ocupados por cátions trivalentes $\left(\mathrm{M}^{3+}\right)$, como o $\mathrm{Al}^{3+} .{ }^{30,39,98}$

Com efeito, as lamelas podem ser eletricamente neutras ou negativamente carregadas, sendo a neutralidade elétrica mantida se na folha tetraédrica existirem apenas cátions de $\mathrm{Si}^{4+}$, e a folha octaédrica for ocupada por cátions trivalentes (geralmente $\mathrm{Al}^{3+} \mathrm{e}$ $\mathrm{Fe}^{3+}$ ) ou divalentes $\left(\mathrm{Fe}^{2+}, \mathrm{Mg}^{2+}, \mathrm{Mn}^{2+}\right)$, para estruturas dioctaédricas e trioctaédricas, respectivamente. A carga negativa é resultante das substituições isomórficas que ocorrem entre os cátions dentro da lamela por outros de valência menor, as quais podem ocorrer na folha octaédrica (por exemplo, $\mathrm{Al}^{3+}$ substituído por $\mathrm{Mg}^{2+}$ ou $\mathrm{Fe}^{2+}$, ou $\mathrm{Mg}^{2+}$ substituído por $\mathrm{Li}^{+}$), ou na tetraédrica (por exemplo, $\mathrm{Si}^{4+}$ substituído por $\mathrm{Al}^{3+}$ ) de forma ordenada, agrupada ou aleatoriamente distribuída. A deficiência de carga positiva gerada é compensada pela presença de cátions de metais alcalinos ou alcalinos terrosos (geralmente $\mathrm{Ca}^{2+}, \mathrm{Mg}^{2+}, \mathrm{K}^{+}$e/ou $\mathrm{Na}^{+}$) no espaço interlamelar ou nas superfícies basais externas, que podem estar hidratados, no caso das esmectitas e vermiculita, por exemplo, ou não hidratados, como na ilita. ${ }^{30,39,62}$

A substituição isomórfica confere a esses materiais uma carga negativa permanente, enquanto uma carga variável é induzida pelas superfícies de borda, associada ao efeito de protonação/desprotonação dos grupos hidroxila presentes nas bordas quebradas das folhas tetraédricas e octaédricas, cujo comportamento é dependente do $\mathrm{pH}$ do meio. Isso posto, os principais sítios de interação envolvem as superfícies externa, interlamelar e de borda. ${ }^{39,62}$

Sendo assim, a química de superfície e interface dos argilominerais, bem como suas propriedades, estão relacionadas ao seu tipo de estrutura, em que fatores como composição química, natureza dos átomos da superfície $(\mathrm{O}$ ou $\mathrm{OH})$, densidade e localização da carga, e tipo de cátion interlamelar exercem influência direta. Diante 
a)

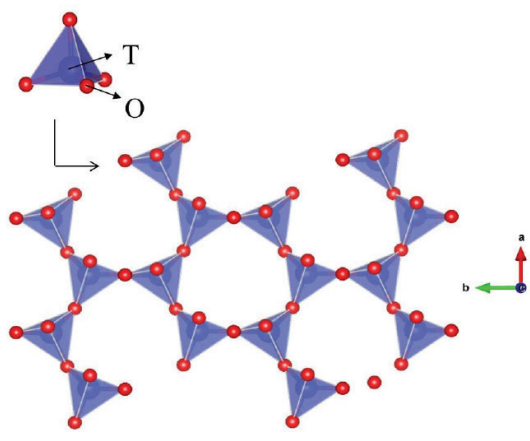

c)

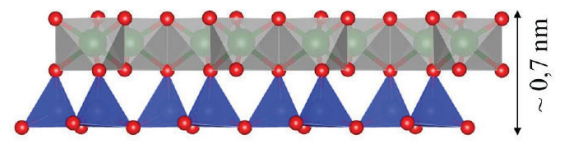

b)

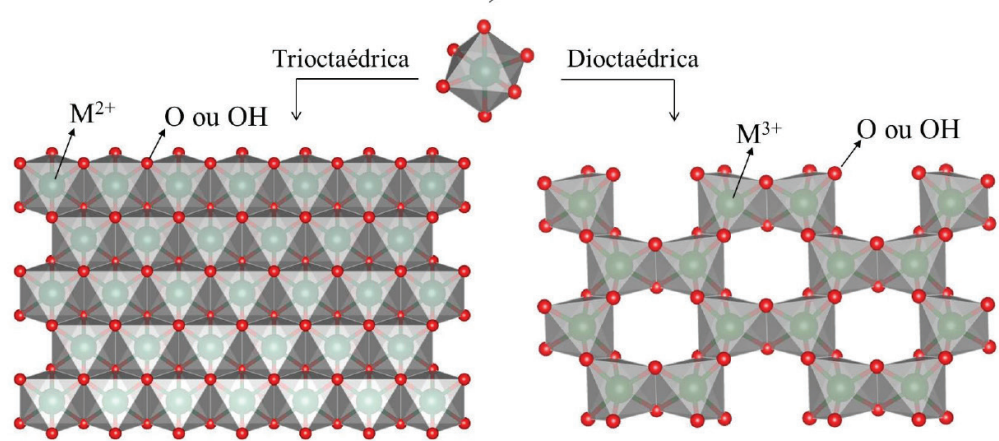

d)

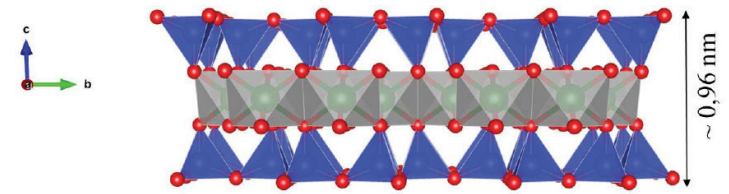

Figura 1. Representação das folhas a) tetraédrica, b) octaédrica, e das lamelas c) 1:1 e d) 2:1 dos argilominerais (Figura gerada com o programa VESTA 3 - ${\text { (ratuito })^{97}}^{9}$

disso, os argilominerais podem apresentar um caráter hidrofílico ou hidrofóbico, exibir diferentes capacidades de troca de cátions (CTC) e, ainda, ser classificados como expansíveis ou não expansíveis. ${ }^{99}$

Tais características são particulares de cada espécie e mostram a imensa versatilidade desses materiais.

\section{Montmorillonita (Mt)}

A Mt é um argilomineral abundante, encontrado na natureza e apontado como um dos principais constituintes das argilas bentonitas. Trata-se de um filossilicato expansível do tipo 2:1, dioctaédrico, pertencente ao grupo das esmectitas, caracterizado por possuir em suas lamelas cátions de $\mathrm{Si}^{4+}$ nos sítios tetraédricos, e íons $\mathrm{Al}^{3+}{\mathrm{e} \mathrm{Mg}^{2+}}^{2+}$ nos sítios octaédricos, gerando um argilomineral de meia fórmula $\mathrm{Si}_{4}\left(\mathrm{Al}_{2-\mathrm{y}} \mathrm{Mg}_{\mathrm{y}}\right) \mathrm{O}_{10} \mathrm{OH}_{2} \mathrm{M}^{\mathrm{n}+}{ }_{\mathrm{y} / \mathrm{n}}-$ em que y é a quantidade de cátions trocáveis (geralmente $\mathrm{Na}^{+}$ou $\mathrm{Ca}^{2+}$ ), que varia entre 0,8 a 1,2, dependendo da extensão da substituição isomórfica do $\mathrm{Al}^{3+}$ pelo $\mathrm{Mg}^{2+}$ na folha octaédrica..$^{30,39}$

A presença de cátions trocáveis confere natureza hidrofílica ao argilomineral, relacionada à existência de moléculas de água agrupadas ao redor deles na região interlamelar. ${ }^{99,100}$ Quando o íon $\mathrm{Na}^{+}$ é o cátion interlamelar, o argilomineral apresenta um espaçamento basal característico em torno de 1,20 nm, e excelentes propriedades de intumescimento em solução aquosa, associadas à expansão das lamelas ao longo da direção de empilhamento. ${ }^{39,62,100}$ Tal característica tem sido extensivamente utilizada como estratégia de modificação química desses materiais, a partir de reações de intercalação em solução aquosa de espécies polares neutras ou catiônicas. ${ }^{101,102}$

Coadunando a definição da IUPAC, ${ }^{1}$ o termo reação de intercalação refere-se a uma reação, geralmente reversível, que envolve a inserção de espécies convidadas em materiais hospedeiros, sem causar grande modificação em sua estrutura. Portanto, no presente caso, o material hospedeiro é a Mt, enquanto que as espécies convidadas podem ser moléculas ou macromoléculas como fármacos, ${ }^{38}$ biopolímeros, ${ }^{46,76}$ surfactantes, ${ }^{37,102}$ entre outras.

No argilomineral, as reações de intercalação podem ser conduzidas por meio de interações eletrostáticas nas quais os íons interlamelares podem ser trocados por outros cátions de natureza orgânica ou inorgânica, ligação de hidrogênio, interações dipolo-dipolo, forças de van der Waals, íon-dipolo, coordenação, entre outros e, geralmente, levam a variações no espaçamento basal. . $^{39,40}$

Nesse sentido, a capacidade de modificação química por meio de reações de intercalação, além de permitir a obtenção de novas funcionalidades, amplia as áreas de aplicação da Mt. Entre elas, a sua utilização como material precursor para obtenção de nanocompósitos poliméricos tem sido alvo de vários estudos, devido à sua capacidade de intercalação de macromoléculas que, aliadas à sua notável estabilidade química, promovem a formação de materiais com propriedades melhoradas. ${ }^{42,43,103}$

\section{BIONANOCOMPÓSITOS: DEFINIÇÃO E ESTRUTURA}

Apesar da existência de bionanocompósitos de origem natural, como os ossos, os dentes, as conchas, o marfim etc., o termo utilizado para designá-los é relativamente recente na literatura. De acordo com a plataforma de busca da Web of Science, o termo bionanocompósito foi utilizado pela primeira vez em 2004, e desde então, o rápido desenvolvimento desses sistemas resultou no aumento progressivo no número de publicações envolvendo o tema. ${ }^{104}$ No entanto, de modo geral, os bionanocompósitos poliméricos são perscrutados desde $1941,{ }^{104}$ enquanto a obtenção desses materiais, especificamente com argilominerais, ocorre desde $1950 .{ }^{105}$

Diante disso, os bionanocompósitos foram, por muito tempo, uma família de nanomateriais pouco examinada e, consequentemente, uma definição universalmente aceita permaneceu ausente. ${ }^{104}$ À vista disso, alguns termos, como materiais híbridos, ${ }^{16,20,106}$ biohíbridos, ${ }^{16,106,107}$ bioplásticos,,$^{16,43}$ nanocompósitos verdes ${ }^{16,71,106}$ ou apenas nanocompósitos, ${ }^{106,107}$ entre outros, foram e ainda são comumente usados na literatura para designar tais sistemas. ${ }^{104}$

O conceito de bionanocompósito foi introduzido na Enciclopédia de Tecnologia Química Kirk-Othmer ${ }^{75}$ em 2008, pelo grupo de pesquisa de Ruiz-Hitzky et al. Porém, antes de inseri-lo, é oportuno entender o significado dos termos material híbrido, argila híbrida e biohíbrido. Segundo a IUPAC, ${ }^{1}$ o termo material híbrido é utilizado para denotar materiais constituídos por uma mistura íntima de componentes inorgânicos, orgânicos ou ambos, geralmente em escalas inferiores a $1 \mu \mathrm{m}$. O híbrido inorgânico-orgânico, portanto, é uma subclasse do material híbrido, no qual a quantidade de componente 
orgânico polimérico é majoritária em relação ao componente inorgânico. ${ }^{1,18}$ Por sua vez, o biohíbrido foi classificado como um material híbrido no qual um dos componentes é de origem biológica. ${ }^{75}$ Vale sobrelevar que o termo argila híbrida, proposto em 2007, pela IUPAC, ${ }^{1}$ constitui um híbrido ou compósito argila-polímero no qual a argila está dispersa em um polímero.

A compreensão desses termos é significativa porquanto os bionanocompósitos foram definidos por Ruiz-Hitzky et al..$^{75}$ como uma classe de materiais híbridos ou biohíbridos originados por sólidos inorgânicos e biopolímeros que interagem em uma escala nanométrica.

Posteriormente, em 2012, a IUPAC ${ }^{104}$ estabeleceu que bionanocompósitos são materiais compósitos formados por constituintes de origem biológica e partículas com pelo menos uma dimensão na faixa de 1 a $100 \mathrm{~nm}$. De acordo com a definição, não apenas os biopolímeros, mas também biomoléculas de baixo peso molecular e microrganismos foram considerados como constituintes de origem biológica. Por cúmulo, quando esses materiais são obtidos com biopolímeros, o termo bionanocompósitos poliméricos torna-se mais adequado para denominá-los.

De fato, em conformidade com a IUPAC, o estudo das interações de montmorillonita com proteínas, reconhecidas como relevantes na área de solos, ${ }^{108} \mathrm{e}$ o trabalho sobre as interações de gelatina com esmectitas, envidado nos anos $1950,{ }^{105}$ são reputados como pioneiros nesse área. ${ }^{75}$ Outro ponto é que consoante a definição mais recente da IUPAC, o que define o termo nanocompósito é a existência de uma fase na faixa nanométrica e, não necessariamente, que a fase preponderante seja o polímero.

As propriedades apresentadas por esses materiais estão intimamente ligadas à sua estrutura e morfologia e, consequentemente, às interações entre as espécies. Portanto, apesar de ser possível a obtenção de microcompósitos, ${ }^{10,69}$ são considerados bionanocompósitos argilomineral/polímero apenas nanocompósitos que possuem estruturas de fase intercalada/delaminada ou esfoliada nas quais são observadas melhores interações entre os componentes iniciais (Figura 2).$^{10}$ Vale ressair que as estruturas representadas na Figura 2 são casos idealizados, de modo que situações intermediárias podem ocorrer. ${ }^{10}$

Nos microcompósitos, não há intercalação do polímero no argilomineral, e a estrutura de fase separada é obtida. ${ }^{10,69}$ Os nanocompósitos com estrutura intercalada são alcançados pela inserção de cadeias poliméricas na região interlamelar do argilomineral, de maneira ordenada, de modo que o empilhamento das lamelas ao longo do eixo basal é mantido. ${ }^{10,69,109}$

Esses nanocompósitos também podem ser chamados de nanocompósitos delaminados, uma vez que a delaminação ocorre quando há separação entre duas lamelas adjacentes do argilomineral, desde que haja certa interação entre elas e manutenção de alguma orientação cristalográfica. ${ }^{10,110}$ Por sua vez, os nanocompósitos com estrutura esfoliada são formados quando há a separação completa e desordenada das lamelas individuais do argilomineral na matriz polimérica. ${ }^{10,69,109}$

A interação entre os biopolímeros e a Mt pode ser impulsionada por diversos mecanismos, a exemplo de troca iônica, ligações de hidrogênio, forças de van der Waals, entre outros. ${ }^{75} \mathrm{~A}$ afinidade entre os materiais de partida é fundamental para alcançar a acomodação e estabilização do polímero na região interlamelar, e de acordo com a natureza das espécies, uma interação mais acentuada pode ocorrer, a partir da utilização de argilas organicamente modificadas. ${ }^{40}$

Devido à excelente propriedade de intumescimento apresentada pela Mt, o procedimento experimental para obtenção dos bionanocompósitos poliméricos geralmente envolve a dispersão inicial do argilomineral em água, em uma etapa de pré-expansão de suas lamelas, que é adotada como estratégia para posterior intercalação do biopolímero. ${ }^{45-47,70}$

De forma geral, a metodologia experimental baseia-se em reações de troca iônica ou adsorção em solução, processos sol-gel ou automontagem, entre outros, em consonância com a natureza do biopolímero, podendo ser modificadas de acordo com as propriedades finais desejadas. ${ }^{10,106}$

A identificação da estrutura formada é feita, principalmente, por meio de técnicas de difração de raios X (DRX) e microscopia eletrônica de transmissão (MET) que, quando aliadas a outras análises, fornecem informações valiosas acerca das interações entre as espécies, a morfologia e a estabilidade térmica e mecânica. ${ }^{11,112}$

Apesar de a definição não ser específica em relação às proporções argilomineral/biopolímero, a dispersão de pequenas quantidades de argilomineral (1-5\% em massa) na matriz polimérica é, geralmente, utilizada para obter bionanocompósitos poliméricos com estabilidade térmica, mecânica, de barreira e etc., superiores às do biopolímero de partida. ${ }^{42,103,113}$

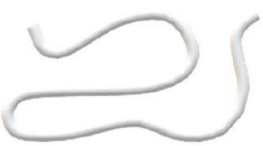

Polímero

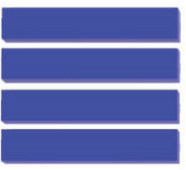

Argilomineral a)

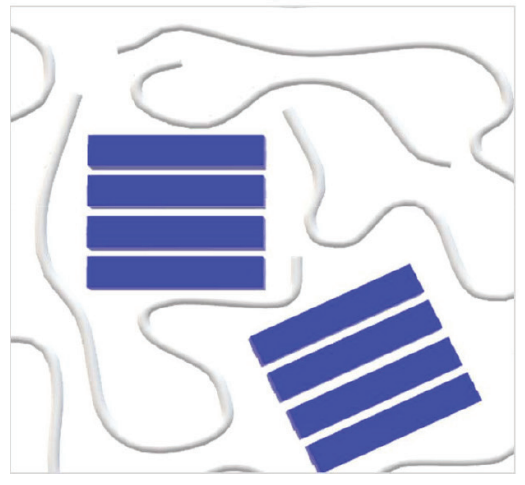

b)

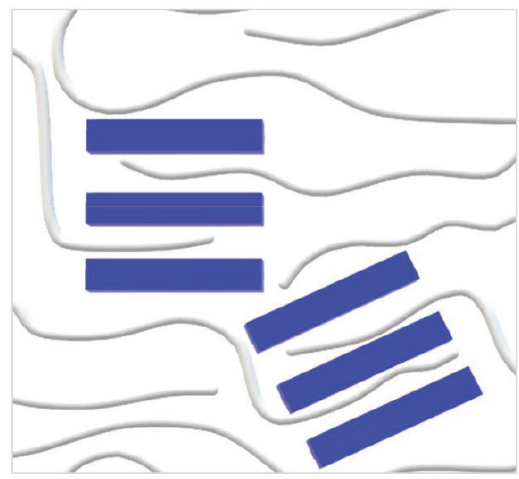

c)

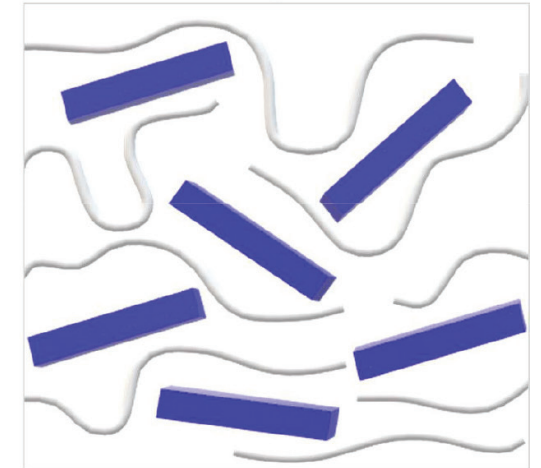

Figura 2. Representações idealizadas do a) microcompósito argilomineral/polímero (estrutura de fase separada) e nanocompósitos argilomineral/polímero com estrutura de fase b) intercalada ou delaminada e c) esfoliada (Figura gerada com o programa CorelDRAW Graphics Suite 2020 - versão de avaliação gratuita) 
Não obstante, os bionanocompósitos baseados em biopolímeros e Mt também podem ser originados quando o material resultante possui maior quantidade do argilomineral em relação ao biopolímero. Todavia, vale salientar que esse é um caso particular, observado apenas para alguns biopolímeros catiônicos, como a quitosana, cuja interação com a Mt origina bionanocompósitos poliméricos ou híbridos de intercalação. ${ }^{46,75,76,78}$

Corroborando a IUPAC, ${ }^{114}$ os compostos de intercalação são definidos como compostos resultantes da inserção reversível, sem ligação covalente, de um tipo de molécula em uma matriz sólida de outro composto, que possui uma estrutura lamelar no qual o composto hospedeiro - um sólido - pode ser macromolecular, cristalino ou amorfo. Uma indicação disso é que, para os bionanocompósitos poliméricos obtidos dessa maneira, os trabalhos referem-se à quantidade de CS adsorvida ou incorporada na Mt, que é possível devido às características estruturais de ambos os componentes.

Em cada caso, a combinação das propriedades funcionais e estruturais apresentadas por ambos leva à obtenção de novos materiais com propriedades superiores às matrizes iniciais, e permite o seu emprego em um vasto campo de aplicação, que vai desde áreas ambientais e biomédicas ao desenvolvimento de dispositivos óptico-eletrônicos. ${ }^{65,70,115,116}$

\section{Bionanocompósitos poliméricos baseados em CS e Mt}

A CS é um copolímero linear constituído, essencialmente, de unidades $\mathrm{N}$-acetil-D-glicosamina e D-glicosamina, unidas por ligações $\beta$-1,4-glicosídicas, obtido pela reação de desacetilação parcial da quitina, um dos polissacarídeos mais abundantes da natureza, juntamente com a celulose, e encontrada em um grande número de organismos vivos, tais como crustáceos, moluscos, insetos, fungos, entre outros, quando o grau de desacetilação (GD) é superior a 50\% (Figura 3a). ${ }^{117-120}$

A extensa utilização do biopolímero deve-se, principalmente, à presença de grupos funcionais em sua estrutura $\left(-\mathrm{OH}\right.$ e $\left.-\mathrm{NH}_{2}\right)$,

a)

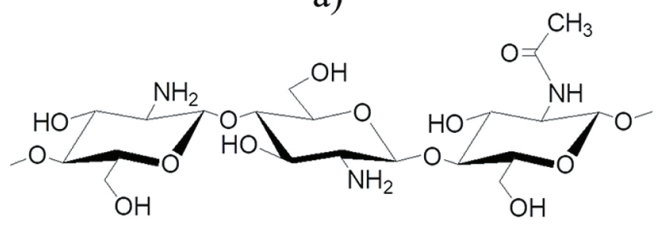

b)

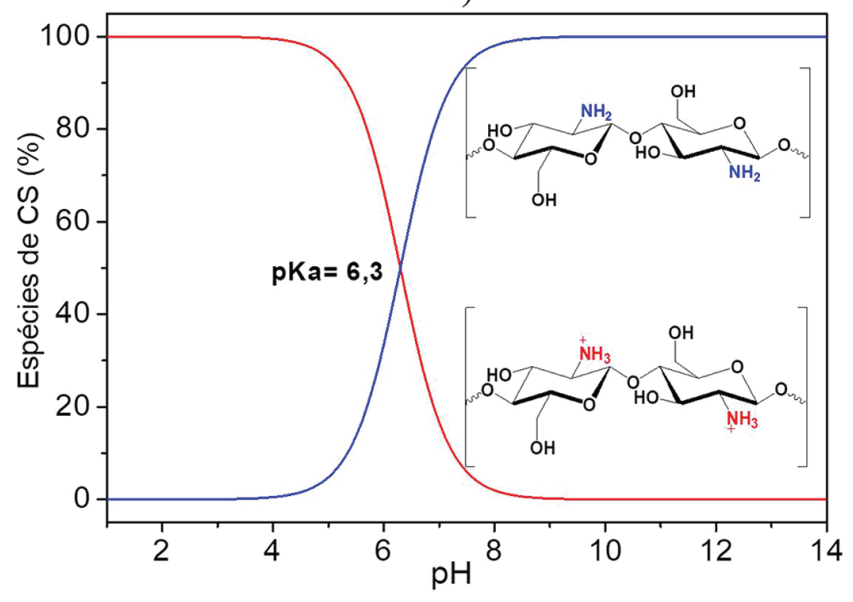

Figura 3. a) Estrutura do fragmento da cadeia polimérica da CS e b) diagrama de variação das espécies de CS em função do pH (Figuras geradas com os programas a) ChemSketch versão gratuita e b) OriginPro ${ }^{\circledR} 2020$ - versão de avaliação gratuita) os quais são responsáveis pela interação com diversas espécies de natureza orgânica ou inorgânica, ${ }^{121-124}$ além de propriedades como bioadesão, biocompatibilidade e atividades antibacteriana e antifúngica, ${ }^{90,94,125}$ que conferem a CS elevado potencial em diversas aplicações biomédicas e farmacológicas..$^{58,126-129}$

Quando dissolvida em soluções aquosas de ácidos diluídos $(\mathrm{pH}<\mathrm{pKa})$, adquire caráter catiônico, devido à protonação dos grupos amino $(\mathrm{pka} \approx 6,3$ ) (Figura $3 \mathrm{~b}),{ }^{119,130}$ e torna-se capaz de interagir com argilominerais expansíveis, como a Mt, por intermédio da intercalação por reações de troca iônica, derivando a formação de bionanocompósitos poliméricos. O mecanismo de intercalação envolve, principalmente, a interação eletrostática entre os grupos amino protonados e as lamelas negativamente carregadas do argilomineral, além de formação de ligações de hidrogênio e outros tipos de interação. ${ }^{20,40}$

A síntese do primeiro bionanocompósito polimérico baseado em CS e Na-Mt foi descrita por Darder et al., ${ }^{46}$ a partir de diferentes proporções CS/Mt em relação à capacidade de troca catiônica (CTC) do argilomineral $\left(76,4 \mathrm{cmol}(+) \mathrm{kg}^{-1}\right)$. Diferentemente da maioria dos nanocompósitos poliméricos, onde o argilomineral é disperso em pequenas quantidades no polímero, os bionanocompósitos poliméricos desse estudo foram obtidos como produto da reação de modificação orgânica da Mt com a CS, originando híbridos de intercalação com maior proporção do argilomineral.

Os difratogramas de raios $\mathrm{X}$ mostraram que quando uma quantidade de CS inferior à CTC foi incorporada na Mt, a variação do valor do espaçamento basal $\mathrm{d}_{001}(1,20$ para $1,45 \mathrm{~nm})$ foi concordante com a intercalação do biopolímero em uma configuração de monocamada. Tendo em conta que a espessura de uma lamela da Mt é cerca de $0,96 \mathrm{~nm}$, atesta-se que o espaço disponível na região interlamelar $\left(\Delta \mathrm{d}_{\mathrm{L}}=0,49 \mathrm{~nm}\right)$ é capaz de acomodar uma camada do polissacarídeo, com espessura igual a $0,38 \mathrm{~nm}$.

A formação dos híbridos foi acompanhada pelo deslocamento da banda referente à deformação dos grupos $\mathrm{NH}_{3}{ }^{+}$nos espectros de infravermelho para menores números de onda, como resultado da interação eletrostática do biopolímero com a Mt. Contudo, esse deslocamento mostrou-se dependente da quantidade de CS adsorvida no argilomineral, e aproximou-se do valor encontrado para os filmes do biopolímero puro $\left(1560 \mathrm{~cm}^{-1}\right)$ quando a quantidade incorporada foi superior à CTC. Nessa condição, o aumento do valor do espaçamento basal $\left(\mathrm{d}_{001}=2,09 \mathrm{~nm}\right)$ correspondeu à intercalação de duas camadas de CS juntamente com os ânions acetato $\left(\Delta \mathrm{d}_{\mathrm{L}}=1,13 \mathrm{~nm}\right)$, compensando a carga excedente do biopolímero intercalado, redundando em uma capacidade de troca de ânions no bionanocompósito formado $\left(57,1 \mathrm{cmol} \mathrm{kg}^{-1}\right)$.

Um esquema representativo é mostrado na Figura 4.

A variação da carga superficial da Mt pela adsorção da CS também foi observada em outros trabalhos. Com base na metodologia descrita por Darder et al. ${ }^{46}$ An e Dultz ${ }^{131}$ obtiveram um bionanocompósito polimérico CS/Mt com capacidade de troca de ânions igual a 43,0 cmol $\mathrm{kg}^{-1}$ quando a quantidade inicial de CS foi igual a $1000 \%$ do valor da CTC da Mt (82,2 cmol(+) $\left.\mathrm{kg}^{-1}\right)$. Nessa composição, o material híbrido apresentou espaçamentos basais de 1,52 e 2,35 nm, de acordo com os resultados obtidos por DRX, associados à intercalação de uma e duas cadeias do polissacarídeo, respectivamente. Outrossim, a quantidade mínima de CS utilizada (20\% da CTC) foi capaz de elevar a carga superficial do sólido resultante em relação à do argilomineral.

$\mathrm{O}$ interesse crescente pelo material incentivou o desenvolvimento de diversos métodos de síntese e obtenção de bionanocompósitos poliméricos CS/Mt sob diferentes formas físicas, além da forma de pó descrita inicialmente por Darder et al. ${ }^{46}$ - entre as quais membranas, filmes, esferas e hidrogéis podem ser citados. Ao contrário do proposto por Darder et al., ${ }^{46}$ esses bionanocompósitos são, geralmente, 


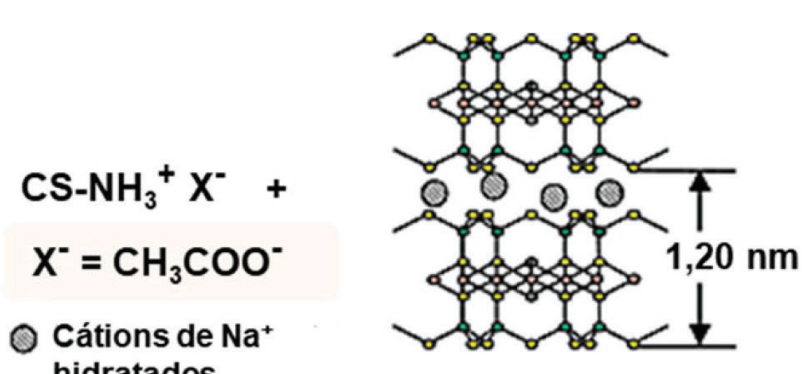

hidratados
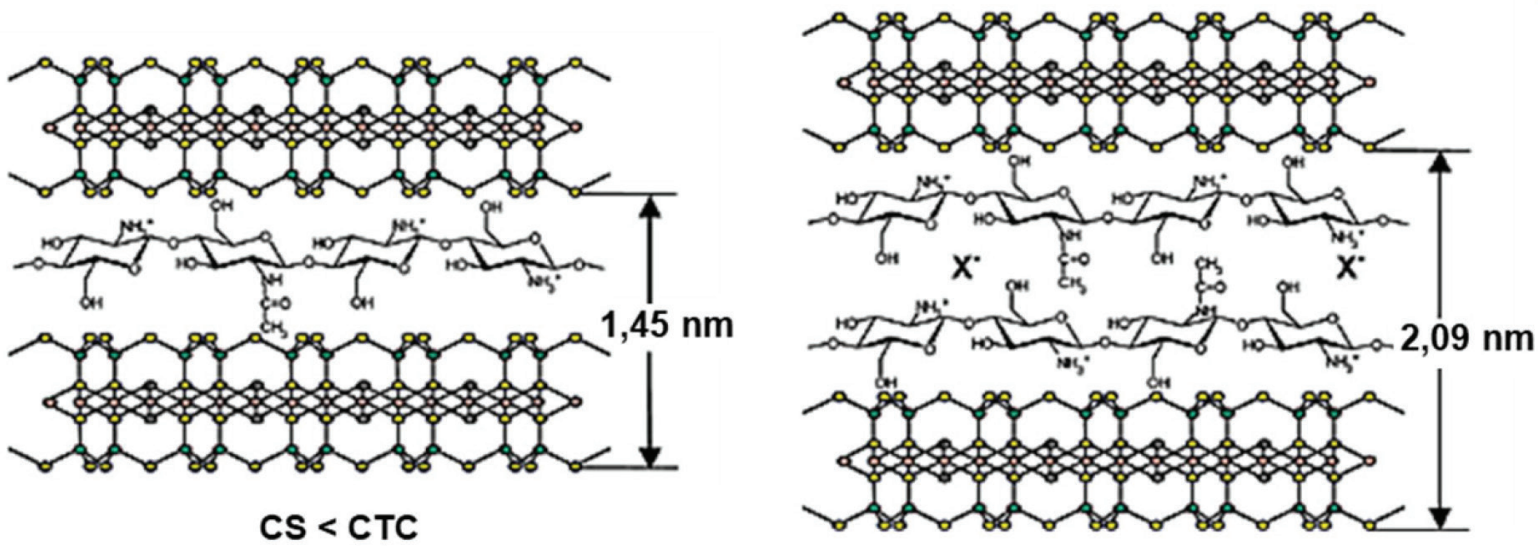

CS $>$ CTC

Figura 4. Esquema representativo da intercalação da CS em Mt em uma configuração de mono e bicamada (Adaptada com permissão da referência 46. Copyright (2003) American Chemical Society)

constituídos por uma elevada quantidade do biopolímero, e a interação com a Mt promove melhorias na estabilidade química ${ }^{64,132} \mathrm{e}$ capacidade intumescimento em água, ${ }^{67}$ assim como nas propriedades mecânicas ${ }^{47,112}$ e térmicas ${ }^{47,89}$ do biopolímero. Nesse caso, dependendo das condições utilizadas, diferentes estruturas podem ser observadas.

Um bionanocompósito polimérico com estrutura esfoliada foi obtido por Wang et al., ${ }^{112}$ ao prepararem um filme de CS/Mt contendo apenas 2,5\% em massa de Mt, pelo método de mistura em solução. Com o aumento da quantidade da matriz inorgânica, 5,0 e 10\% em massa, as estruturas intercaladas foram dominantes, de acordo com os resultados obtidos pelas análises de DRX e MET, e o aumento na estabilidade térmica, na dureza e no módulo de elasticidade foram observados. Além disso, filmes com microestruturas lamelares semelhantes ao nacre, com excelentes propriedades mecânicas, transparência e resistência à chama foram obtidos por Yao et al. ${ }^{47}$ pelo emprego de uma metodologia de automontagem induzida por filtração a vácuo ou evaporação da água.

Os difratogramas de raios X mostraram distâncias basais de 2,6 $\mathrm{nm}$ e as microestruturas em camadas foram observadas por meio de imagens alcançadas por microscopia eletrônica de varredura (MEV) ${ }^{47}$ como ilustrado nas Figuras $5 \mathrm{a}$ e b.

As diferentes estruturas e morfologias adquiridas exercem influência direta nas propriedades finais dos bionanocompósitos poliméricos, e a compreensão acerca de como elas são afetadas tem sido alvo de investigações. Nessa direção, Branca et al. ${ }^{67}$ adotaram a técnica de espectroscopia de infravermelho com transformada de Fourier e reflectância total atenuada (FTIR-ATR) como ferramenta para investigar como as diferentes nanoestruturas formadas nos filmes de CS contendo 2,5 e 5\% em massa de Mt estão relacionadas com a capacidade de intumescimento exibidas pelos respectivos bionanocompósitos poliméricos.

A análise foi dedicada especialmente à região dos espectros referente às vibrações de estiramento $\mathrm{O}-\mathrm{H}$ e N-H $\left(3000-3750 \mathrm{~cm}^{-1}\right)$, e quando comparadas aos espectros de infravermelho do filme de CS pura revelaram que na estrutura intercalada $(5,0 \%$ em massa de Mt) há uma redução das ligações de hidrogênio inter e intramoleculares envolvendo os grupos hidroxila da CS, devido ao arranjo adotado pelas cadeias do polissacarídeo entre as lamelas da Mt, que tendem a maximizar a superfície de contato.

Como consequência, os grupos $\mathrm{OH}$ ficam disponíveis para interagir com as moléculas de água e uma capacidade mais elevada de intumescimento é exibida pelo bionanocompósito. Porém, quando a dispersão homogênea das lamelas do argilomineral ocorre em uma estrutura esfoliada (2,5\% em massa de Mt), os grupos OH da CS estão, provavelmente, envolvidos em uma rede de ligações de hidrogênio e, como consequência, o efeito de intumescimento em água é reduzido.

Diante da relação entre estrutura e propriedades, o efeito da variação da quantidade das matrizes iniciais, condições experimentais (temperatura e $\mathrm{pH}$, condições de preparação da solução da CS), características da CS (massa molar e grau de desacetilação) e da Mt (carga lamelar, CTC e cátions interlamelares) vem sendo averiguado na obtenção dos respectivos bionanocompósitos poliméricos. ${ }^{68,76,77,133,134}$

A influência da relação em massa CS/Mt nas propriedades de superfície dos bionanocompósitos poliméricos foi avaliada por Bensalem et al ${ }^{68}$ por intermédio de medidas de adsorção/dessorção de $\mathrm{N}_{2}$, espectroscopia de fotoelétrons de raios X (XPS) e cromatografia 
a)

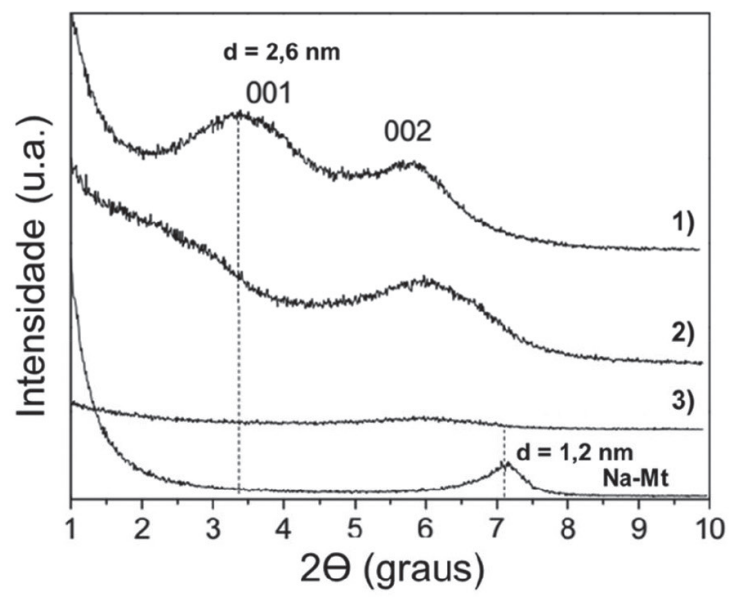

b)
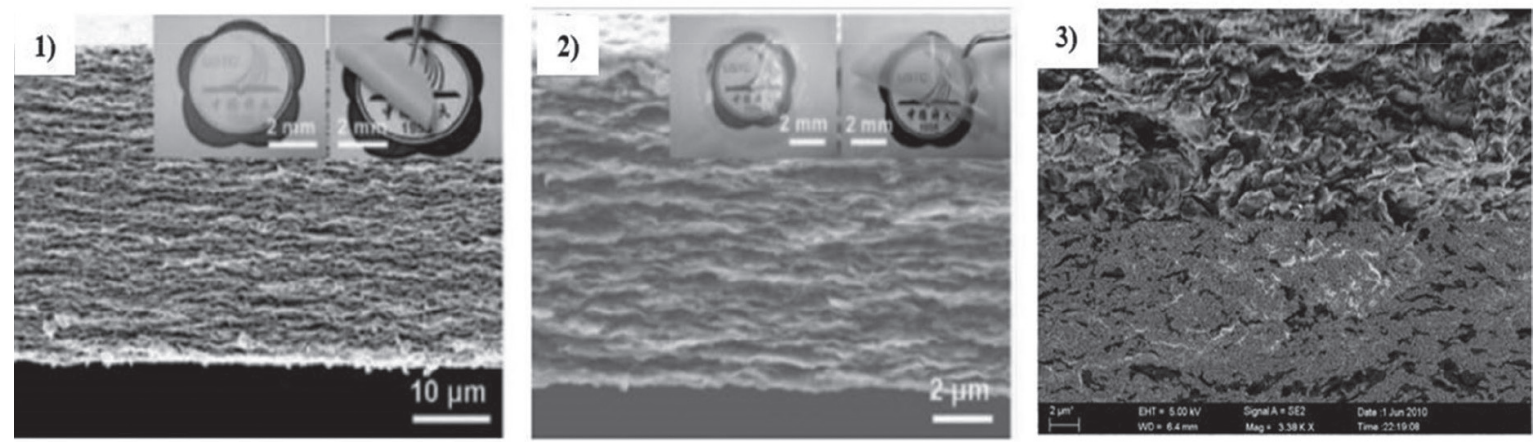

Figura 5. a) Difratogramas de raios X e b) imagens obtidas por MEV da secção transversal dos filmes obtidos pelo método de automontagem induzido por 1) filtração a vácuo e 2) evaporação, e do 3) filme preparado pelo método convencional de simples mistura dos constituintes (Adaptada com permissão da referência 47. Copyright (2010) John Wiley and Sons)

de gás inversa de diluição infinita (IGC-ID) e concentração finita (IGC-FC). Os sólidos foram preparados seguindo a metodologia de Darder et al., ${ }^{46}$ utilizando razões CS/Mt em massa de 0,1/1, 0,5/1, $1 / 1$ e $2 / 1$. A intercalação do biopolímero entre as lamelas da Mt foi confirmada pelos resultados obtidos por DRX, a partir do aumento da distância basal de 1,18 nm (Mt) para 1,46 e 1,54 nm, quando a menor e maior razão CS/Mt foram utilizadas, respectivamente.

A composição química determinada por XPS revelou que a superfície dos materiais híbridos é constituída, principalmente, pelo material inorgânico, e a partir das medidas de adsorção/dessorção de $\mathrm{N}_{2}$, uma diminuição da área superficial específica $\left(\mathrm{A}_{\mathrm{BET}}\right)$ dos sólidos, com o aumento do teor de CS, foi percebida, revelando uma redução de até $50,5 \mathrm{~m}^{2} \mathrm{~g}^{-1}$ em relação à $\mathrm{Mt}$, atribuída à quantidade crescente de biopolímero intercalado.

Os resultados atingidos pelas análises de IGC-ID e IGC-FC sugeriram que a interação da CS com a Mt leva a uma diminuição dos sítios energéticos e da heterogeneidade de superfície do argilomineral com o aumento da quantidade de CS. Ademais, os valores de $\mathrm{A}_{\mathrm{BET}}$ obtidos pelo uso de sondas de n-octano e isopropanol na análise de IGC-FC exibiram um comportamento semelhante ao das isotermas de adsorção/dessorção de $\mathrm{N}_{2}$.

Visando a uma compreensão mais aprimorada acerca dos fatores que interferem na reação de intercalação da CS na Mt, Celis et al. ${ }^{77}$ avaliaram parâmetros como temperatura, natureza da amostra de Mt (composição dos cátions interlamelares), solução e massa molar do biopolímero, mantendo a quantidade de CS (500\% do valor da
CTC) inicial fixa (Tabela 1). Para mais, as amostras de controle foram preparadas (7, 8 e 9) sem a adição de CS, a fim de avaliar as possíveis alterações ocorridas devido aos diferentes procedimentos de preparação.

Dessa forma, a quantidade de ácido utilizada na solução do biopolímero foi escolhida com base no percentual de protonação teórico $(\alpha)$ dos grupos amino, e o elevado percentual de adsorção da CS $(\beta)$, quando a protonação foi de $10 \%$, ocorreu, provavelmente, devido à necessidade de maior quantidade do biopolímero para contrabalancear a carga das lamelas da Mt. Entretanto, para o mesmo valor de $\alpha$ (amostras 4 e 5), a Mt saturada com $\mathrm{Na}^{+}$apresentou maior percentual de CS adsorvida, quando comparada com a amostra bruta, que possui $\mathrm{Ca}^{2+}$ e $\mathrm{Na}^{+}$como cátions interlamelares, patenteando que estes influenciam na capacidade de incorporação do biopolímero na Mt.

Em função da similaridade entre os valores de espaçamento basal, os difratogramas de raios $\mathrm{X}$ foram obtidos para as amostras aquecidas a $200^{\circ} \mathrm{C}$, os quais mostraram reflexões basais em torno de 1,37 nm e 1,0 nm para os bionanocompósitos poliméricos, atribuídas à intercalação da CS em um arranjo de monocamada e presença de algumas lamelas nas quais não houve intercalação, respectivamente, enquanto a Mt e as amostras de controle apresentaram valores de $\mathrm{d}_{001}$ entre 0,96 e $1,0 \mathrm{~nm}$.

A variação de temperatura e massa molar da CS não foram parâmetros relevantes nas condições utilizadas, e as imagens colhidas por MEV para os bionanocompósitos poliméricos denotam que o biopolímero foi igualmente adsorvido na superfície externa da Mt. 
Tabela 1. Condições de síntese dos bionanocompósitos poliméricos CS/Mt (Celis et al., 2011) 77

\begin{tabular}{|c|c|c|c|c|c|}
\hline Amostra & Argila $^{a}$ & Solução de $\mathrm{CS}^{\mathrm{b}}$ & $\alpha^{\mathrm{c}}(\%)$ & $\mathrm{T}\left({ }^{\circ} \mathrm{C}\right)$ & $\beta^{\mathrm{d}}(\%)$ \\
\hline 1 & $\mathrm{Ca}, \mathrm{Na}-\mathrm{Mt}$ & $\mathrm{LC}+\mathrm{CH}_{3} \mathrm{COOH}(30 \mathrm{mmol})+\mathrm{NaOH}(30 \mathrm{mmol})$ & 1000 & 25 & 47 \\
\hline 2 & $\mathrm{Ca}, \mathrm{Na}-\mathrm{Mt}$ & $\mathrm{LC}+\mathrm{CH}_{3} \mathrm{COOH}(30 \mathrm{mmol})+\mathrm{NaOH}(30 \mathrm{mmol})$ & 1000 & 60 & 48 \\
\hline 3 & $\mathrm{Ca}, \mathrm{Na}-\mathrm{Mt}$ & $\mathrm{MC}+\mathrm{CH}_{3} \mathrm{COOH}(30 \mathrm{mmol})+\mathrm{NaOH}(30 \mathrm{mmol})$ & 1000 & 25 & 42 \\
\hline 4 & $\mathrm{Ca}, \mathrm{Na}-\mathrm{Mt}$ & $\mathrm{LC}+\mathrm{CH}_{3} \mathrm{COOH}(3 \mathrm{mmol})$ & 100 & 25 & 76 \\
\hline 5 & $\mathrm{Na}-\mathrm{Mt}$ & $\mathrm{LC}+\mathrm{CH}_{3} \mathrm{COOH}(3 \mathrm{mmol})$ & 100 & 25 & 106 \\
\hline 6 & $\mathrm{Ca}, \mathrm{Na}-\mathrm{Mt}$ & $\mathrm{LC}+\mathrm{HCl}(0,3 \mathrm{mmol})$ & 10 & 25 & 478 \\
\hline 7 & $\mathrm{Ca}, \mathrm{Na}-\mathrm{Mt}$ & $\mathrm{CH}_{3} \mathrm{COOH}(30 \mathrm{mmol})+\mathrm{NaOH}(30 \mathrm{mmol})$ & - & 25 & - \\
\hline 8 & $\mathrm{Ca}, \mathrm{Na}-\mathrm{Mt}$ & $\mathrm{CH}_{3} \mathrm{COOH}(3 \mathrm{mmol})$ & - & 25 & - \\
\hline 9 & $\mathrm{Ca}, \mathrm{Na}-\mathrm{Mt}$ & $\mathrm{HCl}(0,3 \mathrm{mmol})$ & - & 25 & - \\
\hline
\end{tabular}

${ }^{\mathrm{a}} \mathrm{Ca}$, Na-Mt e Na-Mt: Mt bruta e saturada com íons sódio; bC: CS de massa molar baixa (50,000-190,000 g mol $\left.{ }^{-1}\right)$; MC: CS de massa molar média (190,000-310,000 $\left.\mathrm{g} \mathrm{mol}^{-1}\right)$; ${ }^{\mathrm{C}}$ Percentual de protonação teórico dos grupos amino; ${ }^{d}$ Percentual de CS adsorvida em relação CTC da Mt $\left(76,4 \mathrm{cmol}(+) \mathrm{kg}^{-1}\right)$ considerando todos os grupos $-\mathrm{NH}_{2}$ como protonados.

Nessa direção, Hu et al. ${ }^{134}$ examinaram o efeito do $\mathrm{pH}$ na interação entre a CS e Mt, utilizando amostras de CS de baixa e média massa molar (LC e MC), que foram dissolvidas em uma solução de $\mathrm{HCl} 1 \mathrm{~mol} \mathrm{~L}^{-1}$. Os resultados indicam que as quantidades de $\mathrm{LC} \mathrm{e}$ MC adsorvidas aumentaram com o $\mathrm{pH}$, sendo os valores máximos obtidos de $207 \mathrm{mg} \mathrm{g}^{-1}$ e $183 \mathrm{mg} \mathrm{g}^{-1}$, respectivamente, em pH 5,5, correspondendo a cerca de $120 \%$ do valor da CTC da Mt e atribuídas às diferentes contribuições da densidade de carga do biopolímero e ao efeito de competição com os íons $\mathrm{H}_{3} \mathrm{O}^{+}$na faixa de $\mathrm{pH}$ de 3-5,5.

Apesar do elevado valor de $\mathrm{d}_{001}$ observado para os bionanocompósitos poliméricos nos difratogramas de raios $\mathrm{X}$ obtidos a $40{ }^{\circ} \mathrm{C}$ ( $d=1,77$ e 1,80 nm para LC/Mt e MC/Mt), a intercalação de apenas uma monocamada de CS foi considerada, com base na diminuição do espaçamento basal com o aumento da temperatura.

De fato, a literatura reporta que o início da degradação térmica da CS intercalada em Mt ocorre a cerca de $200{ }^{\circ} \mathrm{C}$, $46,68,115$ temperatura na qual os bionanocompósitos poliméricos revelaram distâncias basais de 1,64 nm (LC/Mt) e 1,62 nm (MC/Mt), inferiores ao valor necessário para a acomodação de uma bicamada de polissacarídeo $\left(\mathrm{d}_{001}=1,72 \mathrm{~nm}\right)$, porém maiores que os auferidos por Celis et al. ${ }^{77}$ à mesma temperatura.

Além dos parâmetros de quantidades dos constituintes e da massa molar do biopolímero, Lertsutthiwong et al. ${ }^{133}$ investigaram a influência do grau de desacetilação (GD) da CS (80 e 90\%) nas características finais do bionanocompósito polimérico, a partir de uma razão CS/Mt em massa igual a $0,5 / 1$. A variação do GD foi refletida principalmente na quantidade de CS adsorvida na Mt, que foi superior quando a CS com menor grau de desacetilação foi empregada.

As características da Mt, como carga lamelar e CTC, podem influenciar de modo idêntico no arranjo interlamelar e na incorporação da $\mathrm{CSS}^{76}$ Neste estudo, foram aplicadas duas montmorillonitas de procedências distintas, $\mathrm{Mt}_{(\mathrm{SWy}-2)}$ com baixa carga lamelar e $\mathrm{CTC}=75,9 \mathrm{cmol}(+) \mathrm{kg}^{-1}$ (Wyoming, EUA), e $\mathrm{Mt}_{(\mathrm{SAz}-1)}$ de alta carga lamelar e CTC $=129,3$ (Arizona, EUA). Os bionanocompósitos poliméricos foram obtidos segundo a metodologia descrita por Darder et al. ${ }^{46}$ utilizando diferentes quantidades de CS em relação à CTC (25-1000\%) de cada amostra de Mt. Como a interação entre o biopolímero e a Mt é controlada, principalmente, por troca iônica, a amostra $\mathrm{Mt}_{(\mathrm{SAz}-1)}$, que possui elevadas CTC e carga lamelar, exibiu capacidade de adsorção máxima da CS de $160 \mathrm{mg} \mathrm{g}^{-1}$, superior ao valor observado para $\mathrm{Mt}_{\left(\mathrm{SWy}_{\mathrm{y}-2)}\right.}\left(115,0 \mathrm{mg} \mathrm{g}^{-1}\right)$.

Apesar da diferença entre os valores, a quantidade máxima de CS incorporada foi suficiente para exceder a CTC de cada amostra correspondente de Mt em, aproximadamente $20 \%$, enquanto nos trabalhos de Darder et al. ${ }^{46}$ e An e Dultz ${ }^{131}$ esse excesso chegou a cerca de $75 \%$ e $51 \%$, respectivamente. Ademais, as distâncias basais máximas dos bionanocompósitos poliméricos, de acordo com os resultados obtidos por DRX, foram 2,12 nm para $\mathrm{Mt}_{(\mathrm{Swy}-2)}$ e 1,89 e $1,63 \mathrm{~nm}$ para $\mathrm{Mt}_{(\mathrm{SAz}-1)}$, ilustrando que o arranjo do biopolímero na região interlamelar não está relacionado apenas à quantidade de CS incorporada, mas também à CTC e magnitude de carga lamelar de cada amostra de $\mathrm{Mt}^{76}$

Diante dos resultados expostos pela literatura (Tabela 2), concebe-se que diversos fatores experimentais e estruturais podem influenciar a quantidade de CS intercalada na Mt e estrutura formada. Contudo, apesar de várias investigações, foi possível observar que mesmo conhecendo como alguns fatores experimentais e estruturais da CS e Mt podem direcionar certas propriedades finais dos bionanocompósitos poliméricos formados, a reprodutibilidade dos resultados entre os trabalhos torna-se difícil, mesmo quando condições de síntese similares são empregadas.

Isso ocorre especialmente porque como a CS e a Mt são materiais de origem natural, cada trabalho dispõe de amostras diferentes e, consequentemente, os bionanocompósitos poliméricos originados também diferirão entre si.

Alguns trabalhos são citados na Tabela 2, no que se refere às características da Mt e CS adotadas, assim como às quantidades de quitosana adsorvida (q) e distâncias basais obtidas. Todos os bionanocompósitos poliméricos foram obtidos como descrito inicialmente por Darder et al., ${ }^{46}$ a pH 5,0 e com concentrações iniciais (qi) do polissacarídeo $\geq 500 \%$ do valor da CTC da Mt utilizada.

Outras variações na síntese de bionanocompósitos poliméricos de CS/Mt consistem, ainda, na utilização de agentes reticulantes, entre os quais tripolifosfato de sódio, ${ }^{64,81}$ hidróxido de sódio, ${ }^{137}$ glutaraldeído, ${ }^{65,79,80,138,139}$ e genipina ${ }^{140}$ já foram descritos. A escolha de agentes reticulantes geralmente depende da aplicação desejada, uma vez que os materiais híbridos obtidos podem exibir melhores propriedades mecânicas e estabilidade, ou até mesmo novos sítios de interação, de acordo com a natureza do reticulante..$^{65,140}$

Sem embargo, para aplicações farmacêuticas e biomédicas, por exemplo, existem preocupações quanto ao uso de alguns agentes reticulantes, principalmente o glutaraldeído, uma vez que podem alterar a biocompatibilidade do nanocompósito. ${ }^{141,142}$

\section{Aplicações}

Muitas aplicações dos bionanocompósitos poliméricos de CS/Mt são resultantes de suas propriedades, de forma que o controle 
Tabela 2. Características das Mt e CS utilizadas, quantidade adsorvida ( $\mathrm{q}_{\mathrm{cs}}$ ) e espaçamento basal $\mathrm{d}_{001}$ dos bionanocompósitos poliméricos na forma de pó

\begin{tabular}{|c|c|c|c|c|c|c|c|}
\hline Argila & $\begin{array}{c}\text { CTC } \\
\left(\mathrm{cmol}(+) \mathrm{kg}^{-1}\right) \\
\end{array}$ & GD $(\%)$ & $\begin{array}{c}\mathrm{MM}_{\mathrm{CS}^{\mathrm{a}}} \\
\left(\mathrm{g} \mathrm{mol}^{-1}\right)\end{array}$ & $\mathrm{t}(\mathrm{h})$ & $\begin{array}{c}\mathrm{q}_{\mathrm{cs}} \\
\left(\mathrm{cmol} \mathrm{kg}{ }^{-1}\right)\end{array}$ & $\mathrm{d}_{001}(\mathrm{~nm})$ & Referência \\
\hline Na-Mt & 76,4 & 75,0 & alta & 48 & 180,8 & 2,09 & Darder et al. ${ }^{46,78}$ \\
\hline Na-Mt & & & & & 81,0 & & \\
\hline $\mathrm{Ca}, \mathrm{Na}-\mathrm{Mt}$ & 82,0 & 74,0 & alta & 48 & 169,0 & 2,35 e 1,52 & An e Dultz ${ }^{131}$ \\
\hline Na-Mt & 100 & 82,5 & baixa & 24 & 102,4 & 2,21 e 1,36 & Monvisade e Siriphannon 135 \\
\hline $\mathrm{Ca}, \mathrm{Na}-\mathrm{Mt}$ & 76,4 & 80,0 & baixa & 24 & 58,0 & 1,50 & Celis et al.$^{77}$ \\
\hline $\mathrm{Na}-\mathrm{Mt}$ & & & & & 81,0 & 1,50 & \\
\hline \multirow[t]{3}{*}{$\mathrm{Na}-\mathrm{Mt}$} & 100 & 80,0 & baixa & 48 & & 2,22 & Joshi et al. ${ }^{136}$ \\
\hline & & & média & & 113,6 & 1,80 & \\
\hline & 86,5 & 80,0 & média & 48 & 104,3 & 1,54 & Bensalem et al. ${ }^{68}$ \\
\hline Mt & 90 & 86,0 & alta & 6,0 & - & 1,42 & Li et $a l^{45}$ \\
\hline $\mathrm{Mt}_{(\mathrm{SAz}-1)}$ & 129,3 & $>75,0$ & alta & 48 & $\sim 155,0$ & 1,89 e 1,63 & Koutsopoulou et al. ${ }^{76}$ \\
\hline $\mathrm{Mt}_{(\mathrm{SWy}-2)}$ & 75,9 & & & & $\sim 91,1$ & 2,12 & \\
\hline
\end{tabular}

${ }^{\mathrm{a}}$ Massa molar da CS alta $\left(342500 \mathrm{~g} \mathrm{~mol}^{-1}\right)$, média $\left(190000-310000 \mathrm{~g} \mathrm{~mol}^{-1}\right)$ e baixa $\left(50\right.$ 000-190 $\left.000 \mathrm{~g} \mathrm{~mol}^{-1}\right)$.

das condições de síntese é inescusável para a obtenção das características desejadas. A capacidade de interação com espécies aniônicas, que podem ser inseridas quando a quantidade de CS no bionanocompósito polimérico é superior à CTC da Mt ou, ainda, em meio ácido $(\mathrm{pH}<\mathrm{pKa})$, quando os grupos amino se tornam protonados, permite a utilização deste na detecção potenciométrica de ânions, ${ }^{46,78}$ adsorção de ácido tânico, ${ }^{131}$ remoção de corantes aniônicos do meio aquoso - como o vermelho congo, ${ }^{80}$ amido black $10 \mathrm{~B},{ }^{79}$ azul de remazol, ${ }^{64}$ azul reativo $21,{ }^{143}$ vermelho reativo $141^{143} \mathrm{e}$ vermelho reativo $136^{45}$ - inclusive na adsorção de herbicidas, como quincloraque ${ }^{144} \mathrm{e}$ clopiralide. $^{77}$

Assim, alguns estudos também mostram a utilização desses híbridos na remoção de corantes catiônicos em solução. ${ }^{143,145}$ Todavia, diversas técnicas de caracterização devem ser utilizadas para elucidar os mecanismos de interação que geralmente dependem tanto das caraterísticas finais dos bionanocompósitos poliméricos quanto do comportamento das espécies adsorvidas em solução.

Nessa perspectiva, Vanamudan e Pamidimukkala ${ }^{145}$ recorreram a um bionanocompósito polimérico obtido pela reação entre a CS e uma Mt organicamente modificada com dihidroxietilmetilamônio (Cloisita 30B) para adsorção do corante catiônico rodamina $6 \mathrm{G} \mathrm{em}$ solução, sendo os melhores resultados auferidos na faixa de $\mathrm{pH}$ 10-11, devido aos elevados potenciais negativos do sólido nessa condição. $\mathrm{O}$ mesmo material foi utilizado para a remoção dos corantes aniônicos azul reativo 21 e vermelho reativo 141, os quais mostraram melhor retenção na faixa ácida de $\mathrm{pH}$ (2 5), onde o sólido exibiu uma carga superficial positiva. ${ }^{143}$ Os resultados mostram, igualmente, a estabilidade química dos bionanocompósitos poliméricos em uma ampla faixa de $\mathrm{pH}$ frente à $\mathrm{CS}$ pura, que é solúvel em pH ácido.

Um estudo recente de Li et al..$^{45}$ avaliou a viabilidade de utilização de um bionanocompósito polimérico CS/Mt na remoção do corante aniônico vermelho reativo 136 em solução aquosa. Assim, mostrou, mediante os resultados obtidos por espectroscopia de infravermelho com transformada de Fourier (FTIR), que os grupos $\mathrm{OH}, \mathrm{CONH}$, $\mathrm{NH}$ e $\mathrm{SiO}$ do material híbrido estavam possivelmente envolvidos no mecanismo de adsorção. Além da superfície externa, os grupos funcionais presentes na região interlamelar atuaram como sítios de


cuja intercalação foi observada nos resultados obtidos por DRX

O bionanocompósito polimérico removeu até $74,7 \%$ do corante em solução $\left(445,38 \mathrm{mg} \mathrm{g}^{-1}\right)$, e os testes de dessorção demonstraram que o material pode ser regenerado por meio de um tratamento com uma solução de $\mathrm{NaOH} 0,05 \mathrm{~mol} \mathrm{~L}^{-1}$, e consequentemente reutilizado, apontando uma taxa de regeneração de até $60,5 \%$, mesmo após 15 ciclos de adsorção-dessorção. Outrossim, a estabilidade da cor mostrada pelos sistemas bionanocompósitos/corante vem sendo recentemente avaliada, fazendo desses materiais uma nova proposta para a síntese de pigmentos. ${ }^{44,45}$

A versatilidade dos bionanocompósitos poliméricos de CS/Mt está relacionada, ainda, à possibilidade de interação com espécies inorgânicas, tais como cátions de metais de transição - explorada em diversos trabalhos envolvendo a adsorção de $\mathrm{Cr}(\mathrm{VI}),{ }^{116} \mathrm{Pd}(\mathrm{II}),{ }^{65,82,139,146}$ $\mathrm{Cu}(\mathrm{II}),{ }^{81-83} \mathrm{Cd}(\mathrm{II}),{ }^{82} \mathrm{Ni}(\mathrm{II}){ }^{81,83} \mathrm{e} \mathrm{Hg}(\mathrm{II}),{ }^{139}$ onde os grupos $-\mathrm{NH}_{2} \mathrm{e}-\mathrm{OH}$ da CS são indicados como os principais sítios de interação, atuando como bases de Lewis. ${ }^{65,83,87,88}$

No que se refere à aplicação de técnicas de FTIR e XPS, Liu et al. ${ }^{65}$ investigaram os possíveis grupos funcionais envolvidos na adsorção de $\mathrm{Pd}(\mathrm{II})$ em uma membrana de CS/Mt reticulada com glutaraldeído. A formação do bionanocompósito polimérico foi acompanhada por meio dos dados obtidos por DRX, e as isotermas de adsorção indicaram que a capacidade máxima de retenção dos íons Pd(II) pela membrana em solução foi de $193 \mathrm{mg} \mathrm{g}^{-1}$, a pH 2 e $25^{\circ} \mathrm{C}$.

A análise dos espectros de infravermelho sugeriram absorções iniciais em $1593 \mathrm{~cm}^{-1}\left(\delta \mathrm{NH}_{2}\right)$ e $1650 \mathrm{~cm}^{-1}(\nu \mathrm{C}=\mathrm{N})$ na membrana de $\mathrm{CS} / \mathrm{Mt}$, que foram deslocadas para 1577 e $1623 \mathrm{~cm}^{-1}$, respectivamente, após adsorção do Pd(II) como indicativo da participação dos grupos amina e imina no mecanismo de interação. Diante disso, uma avaliação mais detalhada foi cumprida, a partir da deconvolução dos espectros obtidos por XPS de alta resolução, nos quais as variações observadas na energia de ligação dos grupos $-\mathrm{NH}_{3}{ }^{+},-\mathrm{NH}_{2} \mathrm{e}-\mathrm{C}=\mathrm{N}$ indicaram que estes estariam envolvidos na adsorção do $\mathrm{Pd}(\mathrm{II})$.

Aliás, os espectros exibiram dois picos atribuídos ao Pd 3d em cerca de 338,01 e 336,42 eV, designando dois ambientes diferentes para o paládio, relacionados à energia de ligação dos elétrons $\mathrm{Pd} 3 \mathrm{~d}_{5 / 2}$ do $\mathrm{Pd}(\mathrm{II})$ e à complexação formada entre os grupos $-\mathrm{N}=\mathrm{C} /-\mathrm{NH}_{2} \mathrm{e}$ $\mathrm{Pd}(\mathrm{II})$, respectivamente. Além disso, a presença do pico $\mathrm{Cl} 2 \mathrm{p}$ mostrou que o cloreto participa do mecanismo de adsorção, provavelmente formando o complexo $\left(\mathrm{PdCl}_{4}\right)^{2-}$, que interage eletrostaticamente com os grupos $\mathrm{NH}_{3}^{+}$.

Tal capacidade de interação dos bionanocompósitos poliméricos com metais de transição tem ampliado os campos de aplicação desses materiais. Nessa perspectiva, novos catalisadores, baseados 
na imobilização de $\mathrm{Pd}^{87}$ e $\mathrm{Pd} / \mathrm{Cu}(\mathrm{II}),{ }^{88}$ foram desenvolvidos, cujo procedimento experimental consistiu, inicialmente, em uma etapa de adsorção de cátions metálicos no bionanocompósito polimérico de CS/Mt em solução aquosa, seguido de um processo de redução do Pd(II) com etilenoglicol.

A redução do $\mathrm{Pd}(\mathrm{II})(336,5 \mathrm{eV})$ à $\mathrm{Pd}(335,0 \mathrm{eV})$ foi observada pelos resultados adquiridos pela análise de XPS nos dois catalisadores obtidos, assim como pelas imagens alcançadas por MET. Em especial, o catalisador sintetizado apenas pela imobilização de nanopartículas de Pd no bionanocompósito polimérico $\mathrm{CS} / \mathrm{Mt}^{87}$ mostrou um bom desempenho na reação de acoplamento de Heck (reação de acoplamento cruzado $\mathrm{C}-\mathrm{C}$ entre haletos aromáticos e alcenos, geralmente catalisada por compostos de paládio), o qual apresentou boa estabilidade química e elevada capacidade de reutilização, podendo ser reciclado 30 vezes, sem perda significativa da atividade.

Ainda no campo da catálise, os grupos funcionais do biopolímero também tornam possível a obtenção de catalisadores baseados na imobilização covalente de enzimas nos bionanocompósitos poliméricos, geralmente realizada a partir do glutaraldeído como ponte de interação, mediante a formação de uma base de schiff $(-\mathrm{C}=\mathrm{N}-)^{84,86,147}$

Nessa direção, Mardani et al. ${ }^{86}$ utilizaram esferas de CS/Mt para a imobilização de $\alpha$-amilase, uma enzima pertencente ao grupo das hidrolases responsáveis por hidrolisar o amido em moléculas menores, como a glicose, maltose e maltotriose. Como resultado da imobilização, a enzima mostrou melhores rendimentos catalíticos nas faixas de pH's ácida $(3,5$ e 5,0$)$ e alcalina $(8,0)$, e em temperaturas acima de $60{ }^{\circ} \mathrm{C}$, quando comparada a sua forma livre.

A imobilização permitiu, ainda, a reutilização do sistema, que reteve $47 \%$ de sua atividade enzimática, mesmo após cinco ciclos de reuso, além de proporcionar uma capacidade de armazenamento cerca de 13 vezes superior à da enzima livre, demonstrando a estabilidade e viabilidade de uso das esferas.

As novas características e propriedades apresentadas pelos bionanocompósitos poliméricos baseados em CS e Mt, tais como biocompatibilidade, mucoadesão, baixa solubilidade e hidratação em meio ácido, ${ }^{92,94,115,148}$ além de possibilidade de interação com espécies biologicamente ativas, tornam esses materiais excelentes candidatos em aplicações biológicas e farmacêuticas.

Nesse sentido, diversos trabalhos têm investigado o desempenho desses bionanocompósitos como veículos de liberação de fármacos e/ou como agentes bactericidas. O procedimento experimental para obtenção desses sistemas pode consistir na intercalação simultânea da CS e da espécie ativa na Mt, em um processo in situ ou, ainda, em duas etapas, em que a interação com o princípio ativo é realizada após a síntese do bionanocompósito polimérico, em uma metodologia ex situ. Alguns desses sistemas estão descritos na Tabela 3.

As principais vantagens descritas na utilização desses materiais como veículos para fármacos foram: cinética de liberação lenta; ${ }^{94}$ melhoramento da biodisponibilidade; ${ }^{115}$ e diminuição da citotoxicidade $^{91,92}$ e genotoxicidade ${ }^{152}$ do princípio ativo, fazendo com que haja minimização dos efeitos colaterais durante a sua administração.

Vale ressaltar que os bionanocompósitos poliméricos baseados em CS e Mt podem apresentar atividade antibacteriana e antifúngica, mesmo sem adição de espécies ativas ${ }^{89,90} \mathrm{Em}$ particular, quanto ao efeito bactericida e fungicida do material contra as estirpes Pseudomonas syringe pv. tomato DC3000 e Fusarium solani f. sp. Eumartii, respectivamente, caracterizadas por causar danos à plantação de tomates, tornam o sitema interessante, do ponto de vista da utilização na agricultura.

Nesse campo de aplicação, esferas de CS/Mt foram igualmente empregadas como sistemas de liberação de fertilizantes. ${ }^{137,154}$ Portanto, as diversas aplicações apresentadas atestam a versatilidade dos bionanocompósitos poliméricos baseados em Mt e CS.

\section{Bionanocompósitos poliméricos baseados em celulose e Mt}

A celulose é o biopolímero mais abundante da natureza, derivada de diversas fontes, como plantas, madeira, algas, algodão, bactérias, entre outras, e considerada como uma fonte de matéria-prima quase inesgotável para produtos ambientalmente seguros, biocompatíveis e biodegradáveis, além de estar disponível a baixo custo. ${ }^{56,155,156}$

Sua estrutura molecular é constituída por unidades de $\beta$-D-glucopiranose, unidas por ligações $\beta$-1,4-glicosídicas (Figura 6) e grupos hidroxilas nas posições $\mathrm{C} 2, \mathrm{C} 3$ e C6 - responsáveis pela manutenção de sua estrutura linear por meio da formação de ligações

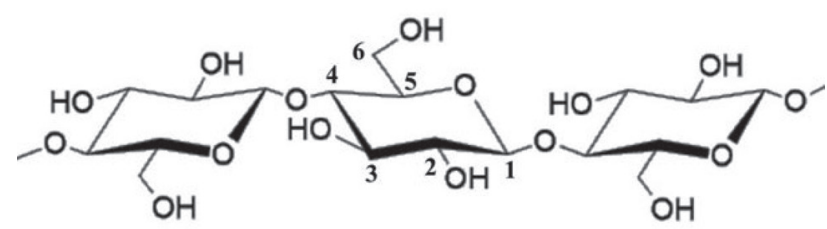

Figura 6. Estrutura do fragmento da cadeia polimérica da celulose (Figura gerada com o programa ChemSketch versão gratuita)

Tabela 3. Bionanocompósitos poliméricos CS/Mt utilizados em aplicações farmacêuticas e biológicas

\begin{tabular}{|c|c|c|c|c|}
\hline Forma física & Espécie ativa & Metodologia & Aplicação & Referência \\
\hline Hidrogel & Vitamina $B_{12}$ & in situ & Sistema de liberação & Liu et al..$^{149}$ \\
\hline Pó & Ácido 5-aminosalisílico & ex situ & & Aguzzi et al..$^{150}$ \\
\hline Hidrogel & Ofloxacina & in situ & & Hua et al. ${ }^{132}$ \\
\hline Pó & Cloridrato de doxorrubicina & in situ & & Yuan et al..$^{151}$ \\
\hline Pó & 5-fluorouracil & in situ & & Kevadiya et al. ${ }^{152}$ \\
\hline Pó & Quinina & ex situ & & Joshi et al. ${ }^{136}$ \\
\hline Pó & Cloridrato de oxitetraciclina & ex situ & $\begin{array}{l}\text { Sistema de liberação/Avaliação da biodisponibilidade oral do } \\
\text { fármaco }\end{array}$ & Salcedo et al..$^{115}$ \\
\hline Pó & Diclofenaco de sódio & in situ & Sistema de liberação/Atividade antibacteriana & Kevadiya et al..$^{153}$ \\
\hline Pó & Digluconato de clorexidina & ex situ & & Onnainty et al..$^{94}$ \\
\hline Pó & Sulfadiazina de prata & in situ & $\begin{array}{c}\text { Curativos para tratamento de feridas cutâneas/Atividade antibac- } \\
\text { teriana }\end{array}$ & Sandri et al..$^{92}$ \\
\hline Filme & Diacetato de clorexidina & in situ & Atividades antimicrobiana e antibiofilme & Ambrogi et al..$^{91}$ \\
\hline Microesferas & Tanshinona IIA & ex situ & Sistema de liberação & Luo et al. ${ }^{95}$ \\
\hline
\end{tabular}


de hidrogênio inter e intramoleculares, que conferem uma excelente estabilidade ao biopolímero e lhe permitem adotar uma estrutura ordenada. ${ }^{119,157}$

O mecanismo de interação entre a celulose e os argilominerais ocorre, principalmente, por intermédio de ligações de hidrogênio e forças de van der Waals, ${ }^{40}$ e a maioria dos trabalhos são destinados à obtenção de materiais com melhores propriedades de barreira, mecânicas, ópticas e retardamento de chama com potencial uso em indústrias elétrica, de alimentos e embalagens. ${ }^{42,43,72,158,159} \mathrm{Com}$ isso, os diversos métodos de síntese geralmente avaliam o efeito da quantidade de Mt na estrutura do bionanocompósito polimérico e, consequentemente, nas propriedades finais.

A propósito, Wang et al. ${ }^{43}$ desenvolveram bioplásticos baseados em bionanocompósitos poliméricos de celulose/Mt, aplicando um método sol-gel e prensagem a quente. A metodologia experimental consistiu, inicialmente, na dissolução do biopolímero em uma solução de LiOH/ureia, seguida de dispersão de certa quantidade de $\mathrm{Mt}$, coagulação com etanol e prensagem do gel formado a $110^{\circ} \mathrm{C}$, originando bionanocompósitos poliméricos contendo 5, 10 e $20 \%$ em massa do argilomineral.

De acordo com os resultados colhidos por MET e DRX, estruturas intercaladas foram formadas, cujas distâncias basais foram de 1,8 nm para todos os materiais obtidos, superiores a da $\mathrm{Mt}\left(\mathrm{d}_{001}=1,4 \mathrm{~nm}\right)$. Os espectros de infravermelho mostraram que a formação do bionanocompósito polimérico foi acompanhada pelo deslocamento da banda $\mathrm{VO}-\mathrm{H}$ para $3427 \mathrm{~cm}^{-1}$, inicialmente presente na celulose em $3377 \mathrm{~cm}^{-1}$, devido às interações entre as espécies, por meio de ligações de hidrogênio. Ademais, os resultados de Espectroscopia de Ressonância Magnética Nuclear de ${ }^{13} \mathrm{C}$ indicaram que a estrutura do biopolímero foi mantida nos bioplásticos.

Como resultado do efeito sinérgico das propriedades da celulose e Mt, os bioplásticos obtidos revelaram propriedades mecânicas e de barreira aos gases $\left(\mathrm{N}_{2}, \mathrm{H}_{2}, \mathrm{CH}_{4}\right.$ e $\left.\mathrm{CO}_{2}\right)$ superiores, que variaram de forma crescente com o aumento de Mt. Todavia, diversos trabalhos têm mostrado que nem sempre as propriedades desses sistemas podem ser explicadas apenas com base na variação da quantidade dos constituintes. ${ }^{19,73,158,160}$

Em seu trabalho, Yang et l. $^{73}$ prepararam filmes de bionanocompósitos poliméricos de celulose/Mt com diferentes proporções, pela dispersão do biopolímero a uma solução de LiOH/ureia/água contendo o argilomineral (5, 10, 15 ou $20 \%$ em massa), seguidos das etapas de regeneração em acetona, lavagem com água e secagem à temperatura ambiente.

Tais bionanocompósitos exibiram melhores propriedades térmicas, mecânicas e de barreira ao $\mathrm{O}_{2}$ em relação aos filmes de celulose pura. No entanto, o filme contendo $15 \%$ em massa de Mt apresentou maior valor de resistência à tração $(187 \mathrm{MPa})$ e ao módulo de Young $(6,1 \mathrm{GPa})$, além de menor teor de umidade e coeficiente de dilatação térmica em relação às outras composições. Concomitantemente, a introdução da Mt forneceu aos filmes certo caráter hidrofóbico, cujas medidas de ângulo de contato evidenciaram valores máximos de $\sim 73^{\circ}$ para aqueles com 10 e $15 \%$ em massa do argilomineral, superior ao observado para os outros filmes de celulose/Mt e celulose pura.

Os materiais foram caracterizados, inclusive, por DRX e MEV, cujos resultados obtidos apontaram aumento do espaçamento basal inicial da Mt de 1,2 $\mathrm{nm}$ para até 1,6 nm, no bionanocompósito polimérico alcançado com maior quantidade do biopolímero, e nanoestruturas lamelares paralelas à superfície do filme, respectivamente.

Essa dependência não linear entre as propriedades mecânicas dos bionanocompósitos poliméricos e o conteúdo da Mt pode ocorrer devido às diferentes organizações estruturais (orientação e distribuição das partículas de Mt), à formação de tactoides e nanoporosidade, que podem ser observadas no material e variam em consonância com o teor do argilomineral. ${ }^{158,161}$

Esses resultados revelam que existe uma composição ideal na qual é possível obter um efeito sinérgico máximo de determinada propriedade, e melhor análise desses sistemas deve ser realizada com vistas a uma compreensão mais acurada das propriedades finais observadas.

Dessa forma, as estruturas formadas desempenham um papel notável no ponto de vista aplicativo, dentre elas, aquelas biomiméticas semelhantes ao nacre ou do tipo tijolo e argamassa denotam uma propriedade especial de barreira aos gases e resistência à chama. A Tabela 4 ilustra alguns desses bionanocompósitos poliméricos.

Tabela 4. Bionanocompósitos poliméricos baseados em celulose e Mt com estruturas semelhantes ao nacre e propriedades de retardação à chama

\begin{tabular}{lc}
\hline Bionanocompósito polimérico & Referência \\
\hline $\begin{array}{l}\text { Filmes celulose nanofibrilada/Mt } \\
\text { Filmes de celulose nanofibrilada } \\
\text { oxidada/Mt }\end{array}$ & Medina et al. ${ }^{158}$ \\
Bioplásticos de celulose/Mt & Ming et al. ${ }^{70}$ \\
Filmes celulose nanofibrilada/Mt & Wang et al. ${ }^{43}$ \\
$\begin{array}{l}\text { Filmes carboximetilcelulose/Mt } \\
\text { Nanopapéis de celulose nanofi- } \\
\text { brilada/Mt }\end{array}$ & Carosio et al. ${ }^{72}$ \\
\hline
\end{tabular}

Nessa perspectiva, Carosio et $a l^{72}$ investigaram os principais mecanismos de proteção contra chama em filmes de celulose nanofibrilada e Mt (10 a 50\% em massa), com estrutura do tipo tijolo e argamassa, por meio de termogravimetria (TG), testes de inflamabilidade e calorimetria do cone. A formação de nanoestruturas lamelares ordenadas e de intercalação do biopolímero entre as lamelas da Mt foi observada por meio de imagens obtidas por MEV e pelos difratogramas de raios $\mathrm{X}$, respectivamente (Figura 7a).

Os resultados revelados pelas análises de TG realizadas em ar revelam que acima de $400{ }^{\circ} \mathrm{C}$, a celulose pura é totalmente oxidada a $\mathrm{CO}$ e $\mathrm{CO}_{2}$. Não obstante, os bionanocompósitos poliméricos apresentaram apenas uma oxidação parcial, uma vez que sua nanoestrutura ordenada funciona como barreia ao $\mathrm{O}_{2}$, retardando a oxidação do carvão formado (Figura 7b).

A partir de testes de inflamabilidade, verificou-se que enquanto o filme de celulose pura inflama imediatamente, aqueles com 30 e $50 \%$ em massa de Mt exibiram um comportamento autoextinguível da chama e, além disso, não inflamaram durante os testes de calorimetria do cone. O resíduo do bionanocompósito polimérico contendo $30 \%$ em massa de Mt, submetido ao teste de chama foi, ainda, examinado quanto à morfologia e composição, onde as imagens obtidas por MEV mostraram a existência de vazios em microescala, resultantes da liberação de produtos voláteis de degradação; os espectros de infravermelho da superfície do resíduo demonstraram bandas características da Mt, enquanto que para os obtidos no centro da amostra, novas bandas relacionadas às estruturas carbonizadas foram observadas. Os resíduos dos filmes de celulose/Mt após o teste de chama são mostrados na Figura 7c.

Segundo a literatura, a estrutura altamente ordenada dos bionanocompósitos poliméricos biomiméticos origina um caminho tortuoso que reduz a difusão do $\mathrm{O}_{2}$, aumentando o efeito de barreira. ${ }^{72,162,164}$

Com base em um método assistido por ultrassom e um processo de automontagem induzido por evaporação da água, Ming et al. ${ }^{70}$ obtiveram filmes de bionanocompósitos poliméricos de celulose nanofibrilada oxidada e Mt, com comportamento autoextinguível da chama e elevada transparência óptica, com potencial para uso em dispositivos óptico-eletrônicos. Os filmes com estrutura semelhante ao 
a)

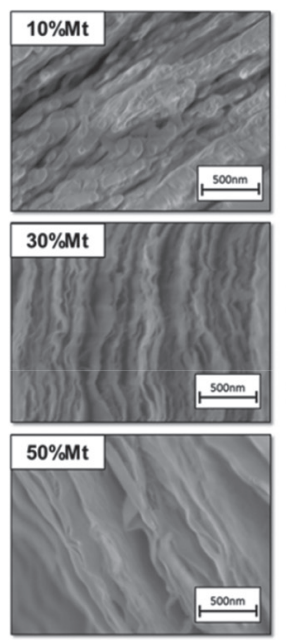

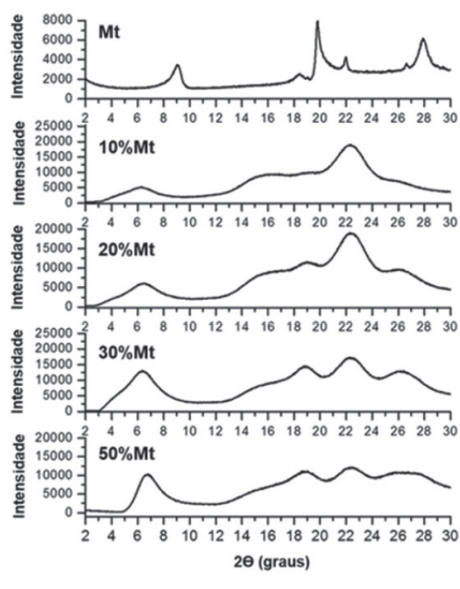

b)

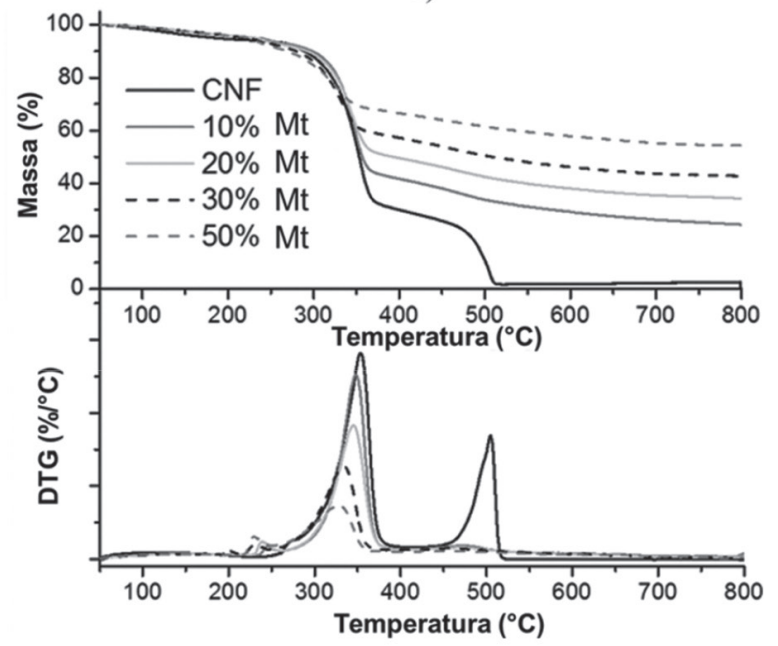

c)

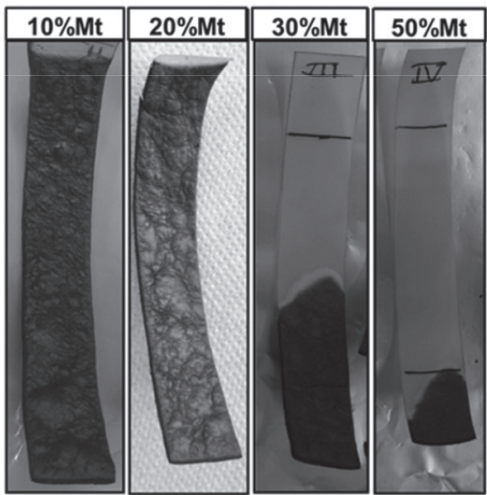

Figura 7. a) Imagens obtidas por MEV e difratogramas de raios X da montmorillonita (Mt) e dos bionanocompósitos poliméricos de celulose/Mt, b) curvas de TG/DTG dos filmes de celulose pura (CNF) e dos bionanocompósitos poliméricos, e c) resíduos coletados dos testes de inflamabilidade dos bionanocompósitos poliméricos (Adaptada com permissão da referência 72. Copyright (2015) American Chemical Society)

nacre, obtidos contendo 5, 10, 30 e 50\% em massa de Mt e espessura de cerca de $50 \mu \mathrm{m}$, mantiveram uma transparência de $90 \%$ a $600 \mathrm{~nm}$, que foi atribuída a uma distribuição homogênea das lamelas da Mt na matriz polimérica ao longo da espessura do filme, conforme indicado pelos resultados obtidos por MEV e DRX.

Assim como observado por Carosio et al. ${ }^{72}$ as composições com 30 e $50 \%$ em massa de Mt exibiram os melhores resultados ao teste de chama, cujo comportamento autoextinguível foi atribuído tanto à já conhecida propriedade de barreira, quanto à estrutura porosa

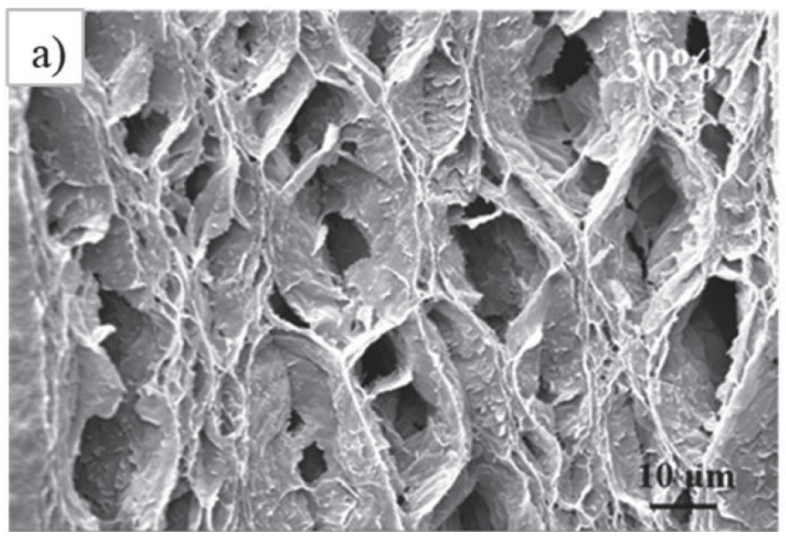

dos resíduos, formada durante a queima (Figura 8), que diminui a condutividade térmica ao longo da espessura.

A obtenção de bionanocompósitos poliméricos baseados em celulose e Mt organicamente modificadas também tem sido relatada na literatura. Mahmoudian et al. ${ }^{103}$ prepararam fibras de celulose regenerada e uma Mt modificada com octadecilamina (OMt), empregando o acetato de 1-etil-3-metilimidazólio como solvente, via processo de fiação úmida. A ausência do pico de difração basal da Mt nos materiais obtidos indicou a esfoliação das lamelas do silicato na

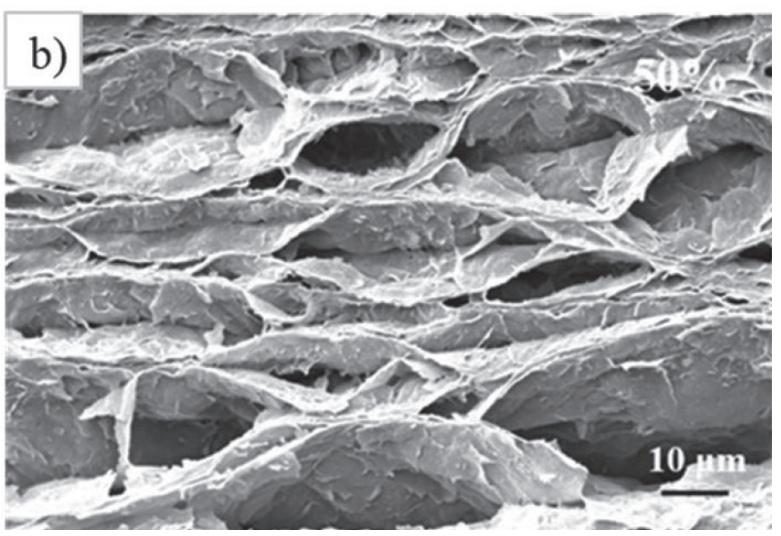

Figura 8. Imagens obtidas por MEV da seção transversal dos filmes de celulose/Mt submetidos ao teste de chama contendo a) $30 \%$ e b) $50 \%$ em massa de Mt (Adaptada com permissão da referência 70. Copyright (2017) American Chemical Society) 
matriz polimérica, e as fibras apresentaram morfologia superficial lisa, de acordo com os resultados obtidos pelas análises de DRX e MEV, respectivamente. Os resultados sugeriram uma boa interação entre as espécies, atribuída às moléculas de octadecilamina intercaladas na Mt, que promovem melhor interação com o polissacarídeo, por meio de ligações de hidrogênio.

Uma vez que os métodos comuns de regeneração da celulose levam à formação de estruturas porosas e amorfas, ideais para o crescimento bacteriano, concebe-se que a obtenção de uma superfície lisa é fundamental, sobretudo quando os bionanocompósitos poliméricos são destinados a aplicações em produtos como alimentos, embalagens ou materiais biomédicos. ${ }^{42,165}$

Nessa direção, Demircan et al..$^{42}$ avaliaram a capacidade dos bionanocompósitos poliméricos de celulose e OMt de inibir o processo de quorum sensing das bactérias, o qual está relacionado à comunicação entre as células bacterianas, mediada por moléculas sinalizadoras extracelulares, denominadas autoindutoras. A celulose foi dissolvida em uma solução de $\mathrm{LiCl} / \mathrm{N}, \mathrm{N}$-dimetilacetamida, e os bionanocompósitos poliméricos, preparados com 1,3 e 5\% em massa de Mt, utilizando o etanol como coagulante.

Os resultados de DRX indicaram, igualmente, certo grau de esfoliação das lamelas, nomeadamente para o material com menor quantidade de OMt. Porém, a presença do pico de difração basal ainda foi observada nos difratogramas de raios $X$ em $2 \theta=3,59^{\circ}$ $\left(\mathrm{d}_{001}=2,46 \mathrm{~nm}\right)$, inferior ao da OMt $\left(2 \theta=4,85^{\circ}, \mathrm{d}_{001}=1,82 \mathrm{~nm}\right)$, indicando a presença de estruturas intercaladas.

A interação entre as espécies, por meio de ligações de hidrogênio, foi verificada em virtude do deslocamento da banda vO-H para regiões de alta frequência nos espectros de infravermelho dos bionanocompósitos poliméricos, e as imagens obtidas por MEV apontaram que entre as composições, aquela com $1 \% \mathrm{em}$ massa de OMt apresentou morfologia de superfície mais lisa, provavelmente devido à melhor interação com as lamelas da OMt. Os bionanocompósitos poliméricos revelaram um efeito anti-quorum sensing contra a bactéria $C$. violaceum CV026, e embora o mecanismo de inibição ainda não tenha sido elucidado, o melhor resultado exibido para a composição com $1 \%$ em massa de OMt pode estar relacionado à estrutura formada.

No entanto, vale salientar que as características encontradas nos bionanocompósitos poliméricos obtidos com OMt podem estar relacionadas ao método de síntese e à quantidade das espécies utilizadas. Todavia, os trabalhos denotam que tanto o método de síntese utilizado quanto a escolha das matrizes iniciais devem ser adotados de acordo com a aplicação destinada.

Embora em menor quantidade, aplicações como adsorção de corantes $^{166}$ e regeneração de tecidos ${ }^{167,168}$ são descritas para os nanocompósitos de celulose/Mt. Outras aplicações utilizam derivados da celulose solúveis em água para obtenção de bionanocompósitos poliméricos com a Mt. Entre eles, a carboximetilcelulose (CMC) é um polissacarídeo aniônico e hidrofílico que apresenta grupos carboximetil substituindo parcialmente as hidroxilas nas posições 2,3 e/ou 6 na estrutura da celulose. ${ }^{169-171}$

Seu uso associado às argilas tem sido destinado tanto à produção de filmes e membranas com melhores propriedades térmicas, mecânicas e de barreira, ${ }^{19,162,172}$ quanto à obtenção de materiais funcionais para aplicações em adsorção de poluentes e sistemas de liberação de fármacos, como mostrado na Tabela 5 . Nesse sentido, a preparação de bionanocompósitos poliméricos é realizada com o intuito de alcançar melhor interação entre as espécies, que pode ser atingida a partir de argilas organicamente modificadas ${ }^{173,174}$ ou adição de reticulantes. ${ }^{66,93}$

Mesmo utilizando a Mt sem modificação, a intercalação da carboximetilcelulose entre as lamelas do argilomineral foi observada. ${ }^{19,162,176,177}$ Nesse caso, os principais mecanismos descritos pela
Tabela 5. Principais aplicações de nanocompósitos de CMC e Mt

\begin{tabular}{|c|c|c|}
\hline Sistema & Aplicação & Referência \\
\hline $\mathrm{CMC} / \mathrm{OMt}^{\mathrm{a}}$ & $\begin{array}{l}\text { Adsorção de vermelho } \\
\text { congo }\end{array}$ & Wang e Wang ${ }^{174}$ \\
\hline $\mathrm{CMC} / \mathrm{Mt} /$ curcumina & $\begin{array}{c}\text { Sistema de liberação de } \\
\text { curcumina }\end{array}$ & Madusanka et al. ${ }^{175}$ \\
\hline $\mathrm{CMC} / \mathrm{OMt}^{\mathrm{b}}$ & $\begin{array}{c}\text { Adsorção de pesticidas } \\
\text { (atrazina, imidaclopride } \\
\text { e tiametoxam) }\end{array}$ & Narayanan et al. ${ }^{173}$ \\
\hline $\begin{array}{c}\text { Esferas CMC/Mt-PPN } \\
\text { reticuladas com cloreto } \\
\text { férrico }\end{array}$ & $\begin{array}{l}\text { Sistema de liberação de } \\
\text { propranolol (PPN) }\end{array}$ & Farhadnejad et al. ${ }^{66}$ \\
\hline
\end{tabular}

${ }^{a}$ Mt modificada com 35 e $45 \%(\mathrm{~m} / \mathrm{m})$ de dimetil dialquil $\left(\mathrm{C}_{14}-\mathrm{C}_{18}\right)$ amina; ${ }^{\mathrm{b}} \mathrm{Mt}$ modificada com brometo de cetiltrimetilamônio (CTAB).

literatura compreendem a formação de ligações de hidrogênio entre os grupos - $\mathrm{OH}$ do biopolímero e a superfície do argilomineral, assim como interações eletrostáticas entre os grupos carboxilatos da $\mathrm{CMC}$, os íons $\mathrm{Ca}^{2+}$ interlamelares e a superfície de borda da Mt. ${ }^{19,162,175}$ Portanto, dependendo da aplicação, deduz-se que o uso de carboximetilcelulose pode ser uma alternativa viável para a substituição da celulose pura.

\section{CONCLUSÃO}

Os bionanocompósitos poliméricos baseados em Mt oferecem uma alternativa viável em diversos campos de aplicação como substituintes ecológicos aos polímeros não biodegradáveis derivados de petróleo. Ademais, mostrou-se que a quitosana pode ser utilizada para atribuir novas funcionalidades ao bionanocompósito. A estrutura formada e a interação entre os constituintes estão diretamente relacionadas com as propriedades finais desses materiais, e alguns trabalhos são dedicados a desenvolver novas metodologias, visando a alcançar as características desejadas.

Apesar de o tema já ser bastante discutido na literatura, os estudos estão geralmente focados na obtenção da composição ideal, de modo que haja um efeito sinérgico das propriedades dos materiais de partida, que é realizado variando a quantidade do argilomineral ou do biopolímero.

Todavia, apenas algumas investigações se propuseram a compreender como a estrutura formada e as interações entre as espécies estão relacionadas com determinada propriedade do bionanocompósito polimérico e, na maioria das vezes, a justificativa utilizada tem sido o aumento do teor de Mt ou a diminuição da quantidade do biopolímero ou vice-versa, embora alguns estudos tenham revelado que nem sempre isso acontece.

No que se refere aos bionanocompósitos poliméricos baseados em CS e Mt, diferentes comportamentos relacionados à estrutura formada têm sido relatados, principalmente entre os valores de espaçamento basal e a quantidade adsorvida. A despeito de essas mudanças poderem ser atribuídas às diferentes metodologias empregadas, as variações das características da Mt e da CS também devem ter contribuição nesse resultado.

Vale salientar que por se tratar de um material natural, a Mt geralmente está presente na argila junto com outras fases, podendo apresentar diferentes capacidades de troca catiônica, carga lamelar e cátions interlamelares $\left(\mathrm{Na}^{+}\right.$e/ou $\mathrm{Ca}^{2+}$ ou, ainda, $\left.\mathrm{Mg}^{2+}\right)$, inclusive conter impurezas de outros metais em sua composição, enquanto as variações observadas para CS estão relacionadas ao grau de desacetilação e à massa molar. Dessa forma, cada sistema proposto é particular, necessita ser devidamente caracterizado e talvez não 
haja uma metodologia fixa para obter um material com determinada característica.

Como observado, os sistemas baseados em CS têm sido mais explorados pela literatura do que aqueles envolvendo celulose. Uma das dificuldades para se trabalhar com a celulose diz respeito à sua alta estabilidade e baixa solubilidade, de modo que para solubilização e obtenção do nanocompósito geralmente é necessário o uso de solventes iônicos polares (LiOH/uréia, LiCl/N,Ndimetilacetamida, entre outros) ou líquidos iônicos, como o acetato de 1-etil-3-metilimidazólio, além de uma etapa de regeneração na qual etanol e acetona, entre outros, são empregados. Por esse motivo, dependendo da aplicação, torna-se mais vantajosa a utilização de derivados solúveis da celulose.

Sem embargo, a funcionalidade dos bionanocompósitos poliméricos é fato e seu campo de aplicação é amplo, envolvendo áreas ambientais, biológicas, farmacêuticas, catalíticas, além de serem utilizados, igualmente, na agricultura, na indústria de alimentos e embalagens, e no desenvolvimento de dispositivos óptico-eletrônicos.

\section{AGRADECIMENTOS}

M. G. Fonseca agradece ao PPGQ/UFPB/CAPES e ao CNPq (Processos 310921/2017-1 e 431727/2016-3) pelo apoio financeiro. D. B. França agradece ao CNPq (Processo 140661/2017-4).

\section{REFERÊNCIAS}

1. Alemán, J.; Chadwick, A. V.; He, J.; Hess, M.; Horie, K.; Jones, R. G.; Kratochvíl, P.; Meisel, I.; Mita, I.; Moad, G.; Penczek, S.; Stepto, R. F. T.; Pure Appl. Chem. 2007, 79, 1801.

2. Blumstein, A.; Bull. Soc. Chim. Fr. 1961, 1, 899.

3. Blumstein, A.; J. Polym. Sci., Part A: Gen. Pap. 1965, 3, 2653.

4. Usuki, A.; Kojima, Y.; Kawasumi, M.; Okada, A.; Fukushima, Y.; Kurauchi, T.; Kamigaito, O.; J. Mater. Res. 1993, 8, 1179.

5. Kojima, Y.; Usuki, A.; Kawasumi, M.; Okada, A.; Kurauchi, T.; Kamigaito, O.; J. Polym. Sci., Part A: Polym. Chem. 1993, 31, 983.

6. Kojima, Y.; Usuki, A.; Kawasumi, M.; Okada, A.; Fukushima, Y.; Kurauchi, T.; Kamigaito, O.; J. Mater. Res. 1993, 8, 1185.

7. Lan, T.; Pinnavaia, T. J.; Chem. Mater. 1994, 6, 2216.

8. Messersmith, P. B.; Giannelis, E. P.; Chem. Mater. 1994, 6, 1719.

9. Lambert, J. F.; Bergaya, F. Em Handbook of Clay Science, Bergaya, F., Lagaly, G., eds.; Elsevier: Amsterdam, 2013, cap. 13.1.

10. Bergaya, F.; Detellier, C.; Lambert, J.-F.; Lagaly, G. Em Handbook of Clay Science, Bergaya, F.; Lagaly, G. eds.; Elsevier: Amsterdam, 2013, cap. 13.

11. Bitinis, N.; Hernandez, M.; Verdejo, R.; Kenny, J. M.; Lopez-Manchado, M. A.; Adv. Mater. (Weinheim, Ger.) 2011, 23, 5229.

12. Pavlidoua, S.; Papaspyrides, C. D.; Prog. Polym. Sci. 2008, 33, 1119.

13. Detellier, C.; Letaief, S. Em Handbook of Clay Science; Bergaya, F., Lagaly, G., eds.; Elsevier Amsterdam, 2013, cap. 13.2.

14. Ruiz-Hitzky, E.; Aranda, P.; Darder, M.; Fernandes, F. M. Em Handbook of Clay Science; Bergaya, F., Lagaly, G., eds.; Elsevier: Amsterdam, 2013, cap. 13.3.

15. Ruiz-Hitzky, E.; Darder, M.; Alcântara, A. C. S.; Wicklein, B.; Aranda, P. Em Functional Polymer Composites with Nanoclays; Lvov, Y., Guo, B., Fakhrullin, R. F., eds.; Royal Society of Chemistry, 2017, cap. 1.

16. Darder, M.; Aranda, P.; Ruiz-Hitzky, E.; Adv. Mater. (Weinheim, Ger.) 2007, 19, 1309.

17. Ray, S. S.; Bousmina, M.; Prog. Mater. Sci. 2005, 50, 962.

18. Unterlass, M. M.; Eur. J. Inorg. Chem. 2016, 1135.

19. Das, P.; Schipmann, S.; Malho, J.; Zhu, B.; Klemradt, U.; Walther, A.; ACS Appl. Mater. Interfaces 2013, 5, 3738.

20. Alcântara, A. C. S.; Darder, M.; Chem. Rec. 2018, 18, 1.
21. Aranda, P.; Fernandes, F. M.; Wicklein, B.; Ruiz-Hitzky, E.; Hill, J. P.; Ariga, K.; Em Bioinspiration Biomimicry Chem. Reverse-Engineering Nature; Swiegers, G. F., ed.; John Wiley \& Sons, 2012, cap.5.

22. Jaber, M.; Komarneni, S.; Zhou, C. -H. Em Handbook of Clay Science; Bergaya, F., Lagaly, G., eds.; Elsevier: Amsterdam, 2013, cap. 7.2.

23. França, D. B.; Torres, S. M.; Filho, E. C. S.; Fonseca, M. G.; Jaber, M.; Chemosphere 2019, 222, 980.

24. Santos, S. S. G.; Pereira, M. B. B.; Almeida, R. K. S.; Souza, A. G.; Fonseca, M. G.; Jaber, M.; J. Hazard. Mater. 2016, 306, 406.

25. Queiroga, L. N. F.; Soares, P. K.; Fonseca, M. G.; Oliveira, F. J. V. E.; Appl. Clay Sci. 2016, 126, 113.

26. Santos, S. S. G.; Silva, H. R. M.; Souza, A. G.; Alves, A. P. M.; Silva Filho, E. C.; Fonseca, M. G.; Appl. Clay Sci. 2015, 104, 286.

27. Perotti, G. F.; Tronto, J.; Bizeto, M. A.; Izumi, C. M. S.; Temperini, M. L. A.; Lugão, A. B.; Parra, D. F.; Constantino, V. R. L.; J. Braz. Chem. Soc. 2014, 25, 320.

28. Perotti, G. F.; Auras, R.; Constantino, V. R. L.; J. Carbohydr. Chem. 2013, 32, 483.

29. Selvam, T.; Inayat, A.; Schwieger, W.; Dalton Trans. 2014, 43, 10365.

30. Brigatti, M. F.; Galán, E.; Theng, B. K. G. Em Handbook of Clay Science; Bergaya, F., Lagaly, G., eds.; Elsevier: Amsterdam, 2013, cap. 2 .

31. Rebitski, E. P.; Alcântara, A. C. S.; Darder, M.; Cansian, R. L.; GómezHortigüela, L.; Pergher, S. B. C.; ACS Omega 2018, 3, 13538.

32. Oliveira, A. S.; Alcântara, A. C. S.; Pergher, S. B. C.; Mater. Sci. Eng., C 2017, 75, 1250.

33. Rebitski, E. P.; Souza, G. P.; Santana, S. A. A.; Pergher, S. B. C.; Alcântara, A. C. S.; Appl. Clay Sci. 2019, 173, 35.

34. Perotti, G. F.; Kijchavengkul, T.; Auras, R. A.; Constantino, V. R. L.; J. Braz. Chem. Soc. 2017, 28, 649.

35. Rossetto, E.; Beraldin, R.; Penha, F. G.; Pergher, S. B. C.; Quim. Nova 2009, 32, 2064

36. Silva, M. M. F.; Oliveira, M. M.; Avelino, M. C.; Fonseca, M. G.; Almeida, R. K. S.; Silva Filho, E. C.; Chem. Eng. J. 2012, 203, 259.

37. Brito, D. F.; Silva Filho, E. C.; Fonseca, M. G.; Jaber, M.; J. Environ. Chem. Eng. 2018, 6, 7080.

38. Cavalcanti, G. R. S.; Fonseca, M. G.; Silva Filho, E. C.; Jaber, M. Colloids Surf., B 2019, 176, 249.

39. Bergaya, F.; Jaber, M.; Lambert, J.-F. Em Rubber-Clay Nanocomposites; Galimberti, M., ed.; John Wiley \& Sons, Inc.: Hoboken, NJ, USA, 2011, cap. 1.

40. Ruiz-Hitzky, E.; Aranda, P.; Darder, M.; Em Tailored Organic-Inorganic Materials; Brunet, E.; Colón, J.L.; Clearfield, A., eds.; John Wiley \& Sons, Inc.: Hoboken, New Jersey, 2015, cap. 6.

41. Nagel, B.; Dellweg, H.; Gierasch, L. M.; Pure Appl. Chem. 1992, 64, 143.

42. Demircan, D.; Ilk, S.; Zhang, B.; Biomacromolecules 2017, 18, 3439.

43. Wang, Q.; Guo, J.; Xu, D.; Cai, J.; Qiu, Y.; Ren, J.; Zhang, L.; Cellulose 2015, 22, 3799.

44. Jimtaisong, A.; Sarakonsri, T.; Int. J. Biol. Macromol. 2019, 129, 737.

45. Li, J.; Cai, J.; Zhong, L.; Cheng, H.; Wang, H.; Ma, Q.; Appl. Clay Sci. 2019, 167, 9 .

46. Darder, M.; Colilla, M.; Ruiz-Hitzky, E.; Chem. Mater. 2003, 15, 3774.

47. Yao, H. Bin; Tan, Z. H.; Fang, H. Y.; Yu, S. H.; Angew. Chem. 2010, 49, 10127.

48. Gao, Y.; Dai, Y.; Zhang, H.; Diao, E.; Hou, H.; Dong, H.; Appl. Clay Sci. 2014, 99, 201.

49. Coativy, G.; Gautier, N.; Pontoire, B.; Buléon, A.; Lourdin, D.; Leroy, E.; Carbohydr. Polym. 2015, 116, 307.

50. Monteiro, M. K. S.; Oliveira, V. R. L.; Santos, F. K. G.; Neto, E. L. B.; Leite, R. H. L.; Aroucha, E. M. M.; Silva, R. R.; Silva, K. N. O.; Food Res. Int. 2018, 105, 637.

51. Magalhães, N. F.; Andrade, C. T.; J. Braz. Chem. Soc. 2010, 21, 202. 
52. Mangiacapra, P.; Gorrasi, G.; Sorrentino, A.; Vittoria, V.; Carbohydr. Polym. 2006, 64, 516.

53. Oliveira, T. Í. S.; Zea-Redondo, L.; Moates, G. K.; Wellner, N.; Cross, K.; Waldron, K. W.; Azeredo, H. M. C.; Food Chem. 2016, 198, 107.

54. Su, X.; Chen, B.; Appl. Clay Sci. 2018, 165, 223.

55. Fernandes, R. S.; Moura, M. R.; Glenn, G. M.; Aouada, F. A.; J. Mol. Liq. 2018, 265, 327.

56. Castro Silva, F.; Silva, M. M. F.; Lima, L. C. B.; Osajima, J. A.; Silva Filho, E. C.; Int. J. Biol. Macromol. 2018, 114, 470.

57. Castro Silva, F.; Silva, M. M. F.; Lima, L. C. B.; Osajima, J. A.; Silva Filho, E. C.; J. Environ. Chem. Eng. 2016, 4, 3348

58. Ferreira, M. O. G.; Leite, L. L. R.; Lima, I. S.; Barreto, H. M.; Nunes, L. C. C.; Ribeiro, A. B.; Osajima, J. A.; Silva Filho, E. C.; Carbohydr. Polym. 2016, 152, 409.

59. Bezerra, R. D. S.; Silva, M. M. F.; Morais, A. I. S.; Santos, M. R. M. C.; Airoldi, C.; Filho, E. C. S.; J. Environ. Chem. Eng. 2014, 2, 605.

60. Pereira, K. A. A.; Osório, L. R.; Silva, M. P.; Sousa, K. S.; Silva Filho, E. C.; Mater. Res. (Sao Carlos, Braz.) 2014, 17, 141.

61. Wang, H.; Qian, J.; Ding, F.; J. Agric. Food Chem. 2018, 66, 395.

62. Tournassat, C.; Bourg, I. C.; Steefel, C. I.; Bergaya, F. Em Natural and Engineered Clay Barriers; Tournassat, C.; Steefel, C. I.; Bourg, I. C.; Bergaya, F., eds.; Elsevier, 2015, cap.1.

63. Lagaly, G.; Ogawa, M.; Dékány, I. Em Handbook of Clay Science; Bergaya, F.; Lagaly, G., eds.; Elsevier: Amsterdam, 2013, cap. 10.3.

64. Pereira, F. A. R.; Sousa, K. S.; Cavalcanti, G. R. S.; França, D. B.; Queiroga, L. N. F.; Santos, I. M. G.; Fonseca, M. G.; Jaber, M.; J. Environ. Chem. Eng. 2017, 5, 3309.

65. Liu, J.; Zheng, L.; Li, Y.; Free, M.; Yang, M.; RSC Adv. 2016, 6, 51757.

66. Farhadnejad, H.; Mortazavi, S. A.; Erfan, M.; Darbasizadeh, B.; Motasadizadeh, H.; Fatahi, Y.; Int. J. Biol. Macromol. 2018, 111, 696.

67. Branca, C.; D’Angelo, G.; Crupi, C.; Khouzami, K.; Rifici, S.; Ruello, G.; Wanderlingh, U.; Polymers 2016, 99, 614

68. Bensalem, S.; Hamdi, B.; Del Confetto, S.; Iguer-Ouada, M.; Chamayou, A.; Balard, H.; Calvet, R.; Colloids Surf., A 2017, 516, 336.

69. Camargo, P. H. C.; Satyanarayana, K. G.; Wypych, F.; Mater. Res. 2009, $12,1$.

70. Ming, S.; Chen, G.; He, J.; Kuang, Y.; Liu, Y.; Tao, R.; Ning, H.; Zhu, P.; Liu, Y.; Fang, Z.; Langmuir 2017, 33, 8455.

71. Darder, M.; Aranda, P.; Ferrer, M. L.; Gutiérrez, M. C.; Del Monte, F.; Ruiz-Hitzky, E.; Adv. Mater. (Weinheim, Ger.) 2011, 23, 5262.

72. Carosio, F.; Kochumalayil, J.; Torino, P.; Site, A.; Michel, V. T.; ACS Appl. Mater. Interfaces 2015, 7, 5847.

73. Yang, Q.; Wu, C. N.; Saito, T.; Isogai, A.; Carbohydr. Polym. 2014, 100, 179.

74. Ruiz-Hitzky, E.; Aranda, P.; Darder, M.; Rytwo, G.; J. Mater. Chem. 2010, 20, 9306.

75. Ruiz-Hitzky, E.; Aranda, P.; Darder, M. Em Kirk-Othmer Encyclopedia of Chemical Technology; John Wiley \& Sons, Inc.: Hoboken, NJ, USA, 2008.

76. Koutsopoulou, E.; Koutselas, I.; Christidis, G. E.; Papagiannopoulos, A.; Appl. Clay Sci. 2020, 190, 105583.

77. Celis, R.; Adelino, M. A.; Hermosín, M. C.; Cornejo, J.; J. Hazard. Mater. 2012, 209-210, 67.

78. Darder, M.; Colilla, M.; Ruiz-Hitzky, E.; Appl. Clay Sci. 2005, 28, 199.

79. Liu, Q.; Yang, B.; Zhang, L.; Huang, R.; Int. J. Biol. Macromol. 2015, 72,1129

80. Huang, R.; Zhang, L.; Hu, P.; Wang, J.; Int. J. Biol. Macromol. 2016, 86, 496.

81. Kameda, T.; Honda, R.; Kumagai, S.; Saito, Y.; Yoshioka, T.; J. Solid State Chem. 2019, 277, 143.

82. Hu, C.; Zhu, P.; Cai, M.; Hu, H.; Fu, Q.; Appl. Clay Sci. 2017, 143, 320.
83. Kameda, T.; Honda, R.; Kumagai, S.; Saito, Y.; Yoshioka, T.; Mater. Chem. Phys. 2019, 236, 121784.

84. Benucci, I.; Liburdi, K.; Cacciotti, I.; Lombardelli, C.; Zappino, M.; Nanni, F.; Esti, M.; Food Hydrocolloids 2018, 74, 124.

85. Kaushal, J.; Seema; Singh, G.; Arya, S. K.; Biotechnol. Rep. 2018, 18, $\mathrm{e} 00258$.

86. Mardani, T.; Khiabani, M. S.; Mokarram, R. R.; Hamishehkar, H.; Int. J. Biol. Macromol. 2018, 120, 354.

87. Zeng, M.; Wang, Y.; Liu, Q.; Yuan, X.; Zuo, S.; Feng, R.; Yang, J.; Wang, B.; Qi, C.; Lin, Y.; ACS Appl. Mater. Interfaces 2016, 8, 33157.

88. Liu, Q.; Xu, M.; Zhao, J.; Yang, Z.; Qi, C.; Zeng, M.; Xia, R.; Cao, X.; Wang, B.; Int. J. Biol. Macromol. 2018, 113, 1308.

89. Han, Y. S.; Lee, S. H.; Choi, K. H.; Park, I.; J. Phys. Chem. Solids 2010, $71,464$.

90. Merino, D.; Mansilla, A. Y.; Casalongué, C. A.; Alvarez, V. A.; J. Agric. Food Chem. 2018, 66, 3101.

91. Ambrogi, V.; Pietrella, D.; Nocchetti, M.; Casagrande, S.; Moretti, V.; Marco, S.; Ricci, M.; J. Colloid Interface Sci. 2017, 491, 265.

92. Sandri, G.; Bonferoni, M. C.; Ferrari, F.; Rossi, S.; Aguzzi, C.; Mori, M.; Grisoli, P.; Cerezo, P.; Tenci, M.; Viseras, C.; Caramella, C.; Carbohydr. Polym. 2014, 102, 970.

93. Sarkar, D. J.; Singh, A.; Carbohydr. Polym. 2017, 156, 303.

94. Onnainty, R.; Onida, B.; Páez, P.; Longhi, M.; Barresi, A.; Granero, G.; Int. J. Pharm. (Amsterdam, Neth.) 2016, 509, 408.

95. Luo, C.; Yang, Q.; Lin, X.; Qi, C.; Li, G.; Int. J. Biol. Macromol. 2019, 125,721 .

96. Teixeira-Neto, É.; Teixeira-Neto, A. A.; Quim. Nova 2009, 32, 809.

97. Momma, K.; Izumi, F. J.; J. Appl. Crystallogr. 2011, 44, 1272.

98. Fonseca, M. G.; Airoldi, C.; Quim. Nova 2003, 26, 699.

99. Schoonheydt, R. A.; Johnston, C. T. Em Handbook of Clay science; Bergaya, F., Lagaly, G. eds.; Elsevier: Amsterdam, 2013, cap. 5.

100. Fonseca, C. G.; Vaiss, V. S.; Wypych, F.; Diniz, R.; Leitão, A. A.; Appl. Clay Sci. 2017, 143, 212.

101. Lopes, C. W.; Penha, F. G.; Braga, R. M.; Araújo Melo, D. M.; Pergher, S. B. C.; Petkowicz, D. I.; Quim. Nova 2011, 34, 1152

102. França, D. B.; Trigueiro, P.; Silva Filho, E. C.; Fonseca, M. G.; Jaber, M.; Chemosphere 2020, 242, 125109.

103. Mahmoudian, S.; Wahit, M. U.; Ismail, A. F.; Balakrishnan, H.; Imran, M.; J. Mater. Sci. 2015, 50, 1228.

104. Shchipunov, Y.; Pure Appl. Chem. 2012, 84, 2579.

105. Talibudeen, O.; Nature 1950, 166, 236.

106. Darder, M.; Aranda, P.; Ruiz-Hitzky, E. Em Environmental Silicate Nano-Biocomposites, Green Energy and Technology; Avérous, L., Pollet, E., eds.; Springer-Verlag: London, 2012, cap. 14

107. Zafar, R.; Zia, K. M.; Tabasum, S.; Jabeen, F.; Noreen, A.; Zuber, M.; Int. J. Biol. Macromol. 2016, 92, 1012.

108. Theng, B. K. G.; Clays Clay Miner. 1982, 30, 1.

109. Coelho, A. C. V.; Santos, P. D. S.; Santos, H. D. S.; Quim. Nova 2007, 30, 1282.

110. Bergaya, F.; Lagaly, G. Em Handbook of Clay Science; Bergaya, F., Lagaly, G., eds.; Elsevier: Amsterdam, 2013, cap. 1.

111. Souza, V. G. L.; Pires, J. R. A.; Rodrigues, P. F.; Lopes, A. A. S.; Fernandes, F. M. B.; Duarte, M. P.; Coelhoso, I. M.; Fernando, A. L.; Food Packaging and Shelf Life 2018, 16, 148.

112. Wang, S. F.; Shen, L.; Tong, Y. J.; Chen, L.; Phang, I. Y.; Lim, P. Q.; Liu, T. X. Polym. Degrad. Stab. 2005, 90, 123.

113. Wypych, F.; Bergaya, F.; Schoonheydt, R. A. Em Surface and Interface Chemistry of Clay Minerals; Schoonheydt, R., Johnston, C. T., Bergaya, F., eds.; Elsevier B.V.: Amsterdam 2018, cap. 10.

114. Moss, G. P.; Smith, P. A. S.; Tavernier, D.; Pure Appl. Chem. 1995, 67, 1307.

115. Salcedo, I.; Sandri, G.; Aguzzi, C.; Bonferoni, C.; Cerezo, P.; SánchezEspejo, R.; Viseras, C.; Colloids Surf., B 2014, 117, 441. 
116. Moussout, H.; Ahlafi, H.; Aazza, M.; El Akili, C.; Int. J. Biol. Macromol. 2018, 108, 1063.

117. Osório, L. R.; Meneguin, A. B.; Silva, H. B.; Barreto, H. M.; Osajima, J. A.; Silva Filho, E. C.; J. Therm. Anal. Calorim. 2018, 134, 1629.

118. Ali, A.; Ahmed, S.; Int. J. Biol. Macromol. 2018, 109, 273.

119. Meier, K. K.; Jones, S. M.; Kaper, T.; Hansson, H.; Koetsier, M. J.; Karkehabadi, S.; Solomon, E. I.; Sandgren, M.; Kelemen, B.; Chem. Rev. (Washington, DC, U. S.) 2018, 118, 2593.

120. Cunha, P. L. R.; Paula, R. C. M.; Feitosa, J. P. A.; Quim. Nova 2009, 32, 649.

121. Airoldi, C.; Quim. Nova 2008, 31, 144.

122. Oliveira, I. R. W. Z.; Fatibello-Filho, O.; Fernandes, S. C.; Vieira, I. C.; Quim. Nova 2009, 32, 1195.

123. Silva, R. C.; Andrade Jr., M. A. S.; Cestari, A. R.; Quim. Nova 2010, 33, 880.

124. Mendes, A. A.; Oliveira, P. C.; Castro, H. F.; Giordano, R. D. L. C.; Quim. Nova 2011, 34, 831 .

125. Ferreira, M. O. G.; Lima, I. S.; Morais, A. Í. S.; Silva, S. O.; Carvalho, R. B. F.; Ribeiro, A. B.; Osajima, J. A.; Silva Filho, E. C.; J. Drug Delivery Sci. Technol. 2019, 49, 375.

126. Laranjeira, M. C. M.; Fávere, V. T.; Quim. Nova 2009, 32, 672.

127. Silva, H. S. R. C.; Santos, K. S. C. R.; Ferreira, E. I.; Quim. Nova 2006, $29,776$.

128. Azevedo, E. P.; Kumar, V.; Quim. Nova 2016, 39, 1071.

129. Delgadillo-Armendariz, N. L.; Rangel-Vazquez, N. A.; Marquez-Brazon, E. A.; Rojas-De Gascue, B.; Quim. Nova 2014, 37, 1503.

130. Froidevaux, V.; Negrell, C.; Caillol, S.; Pascault, J. P.; Boutevin, B.; Chem. Rev. (Washington, DC, U. S.) 2016, 116, 14181.

131. An, J. H.; Dultz, S. Appl. Clay Sci. 2007, 36, 256.

132. Hua, S.; Yang, H.; Wang, W.; Wang, A.; Appl. Clay Sci. 2010, 50, 112.

133. Lertsutthiwong, P.; Noomun, K.; Khunthon, S.; Prog. Nat. Sci.: Mater. Int. 2012, 22, 502.

134. Hu, C.; Deng, Y.; Hu, H.; Duan, Y.; Zhai, K.; Int. J. Biol. Macromol. 2016, 92, 1191.

135. Monvisade, P.; Siriphannon, P.; Appl. Clay Sci. 2009, 42, 427.

136. Joshi, G. V.; Kevadiya, B. D.; Mody, H. M.; Bajaj, H. C.; J. Polym. Sci., Part A: Polym. Chem. 2012, 50, 423.

137. Santos, B. R.; Bacalhau, F. B.; Pereira, T. D. S.; Souza, C. F.; Faez, R.; Carbohydr. Polym. 2015, 127, 340.

138. Gierszewska, M.; Jakubowska, E.; Olewnik-Kruszkowska, E.; Polym. Test. 2019, 77, 105872.

139. Nematidil, N.; Sadeghi, M.; Nezami, S.; Sadeghi, H.; Carbohydr. Polym. 2019, 222, 114971.

140. Liang, B.; Shu, Y.; Wan, P.; Zhao, H.; Dong, S.; Hao, W.; Yin, P.; Compos. Sci. Technol. 2019, 182, 107747.

141. Yuan, Y.; Chesnutt, B. M.; Utturkar, G.; Haggard, W. O.; Yang, Y.; Ong, J. L.; Bumgardner, J. D.; Carbohydr. Polym. 2007, 68, 561.

142. Muzzarelli, R. A. A.; Carbohydr. Polym. 2009, 77, 1.

143. Vanaamudan, A.; Sudhakar, P. P. J.; Taiwan Inst. Chem. Eng. 2015, 55, 145.

144. Ding, C.; Gong, D.; Yu, P.; Shao, J.; Zhong, M.-E. E.; Desalin. Water Treat. 2016, 57, 24970.

145. Vanaamudan, A.; Sudhakar, P. P.; J. Taiwan Inst. Chem. Eng. 2015, 55, 145.

146. Wang, W.; Zhao, Y.; Yi, H.; Chen, T.; Kang, S.; Zhang, T.; Rao, F.; Song, S.; Int. J. Biol. Macromol. 2019, 128, 85.

147. Cacciotti, I.; Lombardelli, C.; Benucci, I.; Esti, M.; J. Mater. Res. Technol. 2019, 8, 3644.
148. Salcedo, I.; Aguzzi, C.; Sandri, G.; Bonferoni, M. C.; Mori, M.; Cerezo, P.; Sánchez, R.; Viseras, C.; Caramella, C.; Appl. Clay Sci. 2012, 55, 131.

149. Liu, K. H.; Liu, T. Y.; Chen, S. Y.; Liu, D. M.; Acta Biomater. 2008, 4, 1038.

150. Aguzzi, C.; Capra, P.; Bonferoni, C.; Cerezo, P.; Salcedo, I.; Sánchez, R.; Caramella, C.; Viseras, C.; Appl. Clay Sci. 2010, 50, 106.

151. Yuan, Q.; Shah, J.; Hein, S.; Misra, R. D. K.; Acta Biomater. 2010, 6, 1140.

152. Kevadiya, B. D.; Patel, T. A.; Jhala, D. D.; Thumbar, R. P.; Brahmbhatt, H.; Pandya, M. P.; Rajkumar, S.; Jena, P. K.; Joshi, G. V.; Gadhia, P. K.; Tripathi, C. B.; Bajaj, H. C.; Eur. J. Pharm. Biopharm. 2012, 81, 91.

153. Kevadiya, B. D.; Rajkumar, S.; Bajaj, H. C. Biocybern. Biomed. Eng. 2015, 35, 120.

154. Messa, L. L.; Froes, J. D.; Souza, C. F.; Faez, R.; Quim. Nova 2016, 39, 1215.

155. Pacheco, G.; Nogueira, C. R.; Meneguin, A. B.; Trovatti, E.; Silva, M. C. C.; Machado, R. T. A.; Ribeiro, S. J. L.; Silva Filho, E. C.; da S. Barud, H.; Ind. Crops Prod. 2017, 107, 13.

156. Perotti, G. F.; Barud, H. S.; Ribeiro, S. J. L.; Constantino, V. R. L.; J. Braz. Chem. Soc. 2014, 25, 1647.

157. Filho, E. C. S.; Lima, L. C. B.; Silva, F. C.; Sousa, K. S.; Fonseca, M. G.; Santana, S. A. A.; Carbohydr. Polym. 2013, 92, 1203.

158. Medina, L.; Nishiyama, Y.; Daicho, K.; Saito, T.; Yan, M.; Berglund, L. A.; Macromolecules 2019, 52, 3131 .

159. Silva Filho, E. C.; Lima, L. C. B.; Silva, F. C.; Sousa, K. S.; Fonseca, M. G.; Santana, S. A. A.; Carbohydr. Polym. 2013, 92, 1203.

160. Ul-Islam, M.; Khan, T.; Park, J. K.; Carbohydr. Polym. 2012, 89, 1189.

161. Zerda, A. S.; Lesser, A. J.; J. Polym. Sci., Part B: Polym. Phys. 2001, 39, 1137.

162. Liu, A.; Berglund, L. A.; Eur. Polym. J. 2013, 49, 940.

163. Liu, A.; Walther, A.; Ikkala, O.; Belova, L.; Berglund, L. A.; Biomacromolecules 2011, 12, 633.

164. Wang, J.; Gardner, D. J.; Stark, N. M.; Bousfield, D. W.; Tajvidi, M.; Cai, Z.; ACS Sustainable Chem. Eng. 2018, 6, 49.

165. Ahmadzadeh, S.; Desobry, S.; Keramat, J.; Nasirpour, A.; Carbohydr. Polym. 2016, 141, 211.

166. Wang, Q.; Wang, Y.; Chen, L.; Carbohydr. Polym. 2019, 210, 314.

167. Sajjad, W.; Khan, T.; Ul-Islam, M.; Khan, R.; Hussain, Z.; Khalid, A.; Wahid, F.; Carbohydr. Polym. 2019, 206, 548.

168. Ul-Islam, M.; Khan, T.; Khattak, W. A.; Park, J. K.; Cellulose 2013, 20, 589.

169. Siqueira, E. J.; Brochier Salon, M. C.; Mauret, E.; Ind. Crops Prod. 2015, 72, 87.

170. Wong, T. W.; Ramli, N. A.; Carbohydr. Polym. 2014, 112, 367.

171. Javanbakht, S.; Shaabani, A.; Int. J. Biol. Macromol. 2019, 133, 21.

172. Oliveira, R. L.; Barud, H. S.; Salvi, D. T. B.; Perotti, G. F.; Ribeiro, S. J. L.; Constantino, V. R. L; Ind. Crops Prod. 2015, 69, 415.

173. Narayanan, N.; Gupta, S.; Gajbhiye, V. T.; Manjaiah, K. M.; Chemosphere 2017, 173, 502.

174. Wang, M.; Wang, L.; Water Sci. Eng. 2013, 6, 272.

175. Madusanka, N.; Silva, K. M. N. N.; Amaratunga, G.; Carbohydr. Polym. 2015, 134, 695

176. Gutiérrez, M. Q.; Echeverría, I.; Ihl, M.; Bifani, V.; Mauri, A. N.; Carbohydr. Polym. 2012, 87, 1495.

177. Kpogbémabou, D.; Gridi-bennadji, F.; Chiên, L.; Ghilardi, S.; Jacquet, A.; Smith, A.; Peyratout, C.; J. Colloid Interface Sci. 2014, 417, 152. 